Argomional laboratory

Analysis of Failed and Nickel-Coated 3093 Beam Clamp Components at the East TennesseeTechnology Park (ETTP)

Nuclear Engineering Division 
About Argonne National Laboratory

Argonne is a U.S. Department of Energy laboratory managed by UChicago Argonne, LLC under contract DE-AC02-06CH11357. The Laboratory's main facility is outside Chicago, at 9700 South Cass Avenue, Argonne, Illinois 60439. For information about Argonne and its pioneering science and technology programs, see www.anl.gov.

\section{Availability of This Report}

This report is available, at no cost, at http://www.osti.gov/bridge. It is also available on paper to the U.S. Department of Energy and its contractors, for a processing fee, from:

U.S. Department of Energy

Office of Scientific and Technical Information

P.O. Box 62

Oak Ridge, TN 37831-0062

phone (865) 576-8401

fax (865) 576-5728

reports@adonis.osti.gov

\section{Disclaimer}

This report was prepared as an account of work sponsored by an agency of the United States Government. Neither the United States Government nor any agency thereof, nor UChicago Argonne, LLC, nor any of their employees or officers, makes any warranty, express or implied, or assumes any legal liability or responsibility for the accuracy, completeness, or usefulness of any information, apparatus, product, or process disclosed, or represents that its use would not infringe privately owned rights. Reference herein to any specific commercial product, process, or service by trade name, trademark, manufacturer, or otherwise, does not necessarily constitute or imply its endorsement, recommendation, or favoring by the United States Government or any agency thereof. The views and opinions of document authors expressed herein do not necessarily state or reflect those of the United States Government or any agency thereof, Argonne National Laboratory, or UChicago Argonne, LLC. 


\title{
ANALYSIS OF FAILED AND NICKEL-COATED 3093 BEAM CLAMP COMPONENTS AT THE EAST TENNESSEE TECHNOLOGY PARK (ETTP)
}

\author{
September 2010
}

\author{
Prepared for \\ Bechtel Jacobs Company, LLC \\ Oak Ridge, TN
}

\section{Prepared by}

Dileep Singh, Kristen Pappacena*, Jose Gaviria, and Tatiana Bursteva Nuclear Engineering Division

*Energy Systems Division

Argonne National Laboratory

9700 S. Cass Avenue

Argonne, IL 60439 


\section{ACKNOWLEDGMENTS}

The work at Argonne National Laboratory was supported by Bechtel Jacobs Company (BJC) under Memorandum Purchase Order 23900-MP-0197. Valuable insights and discussions with various BJC personnel, including Abdul Dada, Tim Carty, Tim Knaub, Kathy Howe, and Robert Seigler, are appreciated. 


\section{CONTENTS}

Acknowledgments......................................................................................................... iii

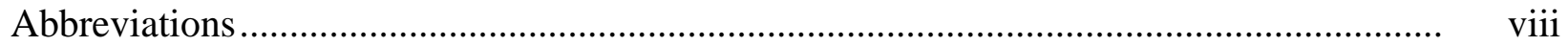

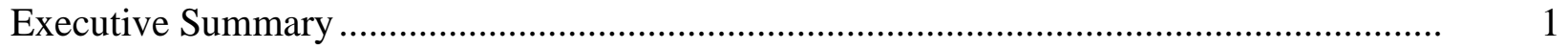

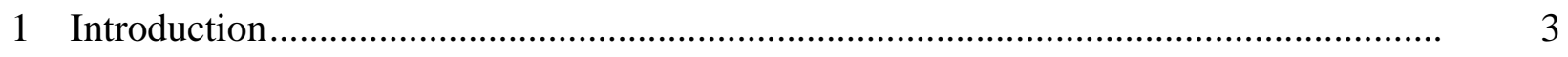

2 Review of Documents Provided by BJC ...........................................................................

3 Sample Description...................................................................................................... 5

4 Hardness Measurements ................................................................................................... 9

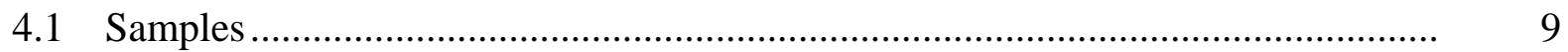

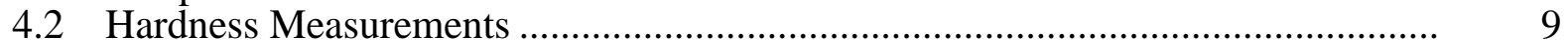

4.3 Summary ………………………………………………………………………. 12

$5 \quad$ Hydrogen Analysis of Steel Samples.............................................................................. 13

5.1 Hydrogen Determination ..................................................................................... 13

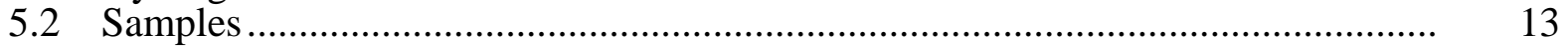

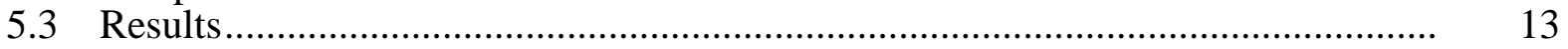

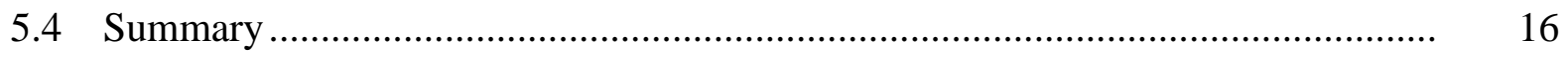

6 Analyses of Failed Yoke.................................................................................................... 17

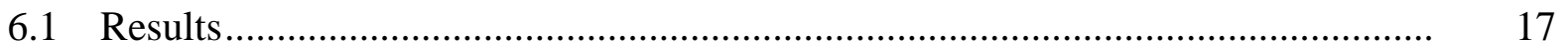

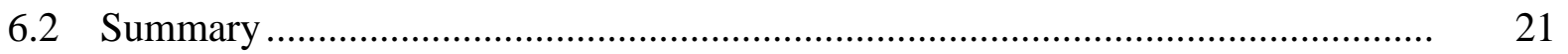

7 Chemical Analysis of Steel and Corrosion Products ......................................................... 22

8 Coating Thickness...................................................................................................... 24

9 Reliance Inspection Plan ............................................................................................... 27

10 Possible Corrosion Mechanism(s) ............................................................................. 28

11 Analysis of Sample WA14........................................................................................ 29

11.1 SEM Analysis on WA14 ............................................................................... 29

11.2 ICP-MS Analysis on WA14 Residue............................................................. 30

11.3 Hardness Measurements on WA14 ................................................................. 30

11.4 Coating Thickness Measurements ........................................................................... 31

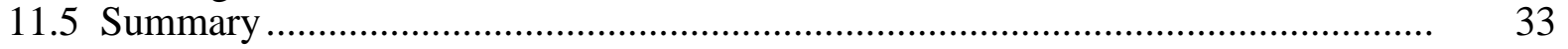

12 Analysis of Samples 10P1 and 10P2 ………………................................................. 34

12.1 Coating Thickness Measurements ........................................................................... 34

12.2 Hardness Measurements ............................................................................ 34

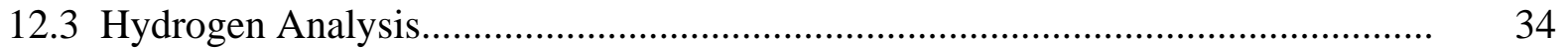




\section{CONTENTS (Cont.)}

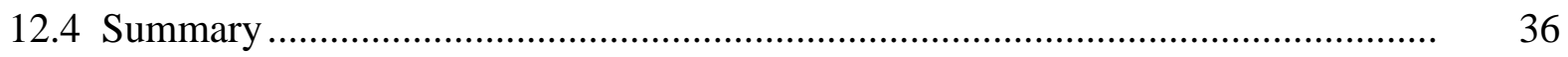

13 Evaluation of Aluminum-Coated Yoke and D-rings ………………………………........ 37

13.1 Hardness Evaluations of Aluminum-Coated Yoke and D-rings.......................... 37

13.2 Coating Thickness Evaluations for Aluminum-Coated Yokes and D-ring ........... 38

13.3 Durability of Aluminum Coating on Yokes and D-rings..................................... 39

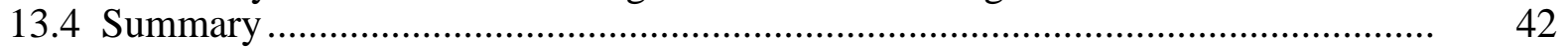

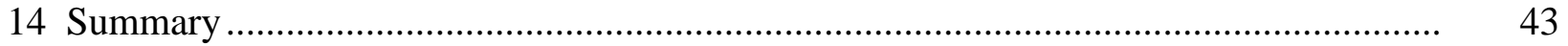

15 References .............................................................................................................. 45

\section{FIGURES}

1 Photograph of Corroded and Failed Yoke Sample \#6YC............................................. 6

2 Higher Magnification of the Corroded and Failed Yoke \#6YC ………........................ 6

3 High Magnification Picture of Fracture Surface of \#6YC Sliver as shown in Figure 1 ........................................................................................................ 7

$4 \quad$ One of “K25 five” Beam Clamp Assemblies Received by ANL …….......................... 7

$5 \quad$ Five As-Received Ni-5\% P Coated Yoke/D-ring Assemblies.......................................... 8

$6 \quad$ Schematic of Cut Yoke Sample for Hardness Measurements ....................................... 10

$7 \quad$ Schematic of D-ring Sample for Hardness Measurements ............................................. 10

$8 \quad$ As-Received Yoke Sample NiARY1 with Indents ........................................................... 10

$9 \quad$ As-Received D-ring Sample NiARDR1 with Indents .................................................... 10

10 Corroded Yoke Sample 2YC with Indents .................................................................... 10

11 Corroded D-ring Sample 2DRC with Indents............................................................. 10

12 Hardness Values of As-Received and Corroded D-rings ............................................... 11

13 Hardness Values of As-Received and Corroded Yokes on the Shiny Side .................. 11

14 Hardness Values of As-Received and Corroded Yokes on the Dull Side .................... 11

15(a) Fractured Edge from Small Piece of Steel.................................................................. 17

15(b) Higher Magnification of Area in Figure 15(a)............................................................ 17 


\section{FIGURES (Cont.)}

16(a) Higher Magnification of Area in Figure 15(b) ........................................................... 18

16(b) EDAX Analysis of the Area Shown in Figure 16(a) .................................................... 18

17(a) Fracture Surface of 2YC, with Area of Corrosion............................................................ 19

17(b) Higher Magnification of the Area Shown in Figure 17(a)............................................ 19

17(c) Higher Magnification of the Image in Figure 17(b) ...................................................... 19

17(d) Presence of Zinc and Sulfur Detected in the EDAX Conducted on the Area of Corrosion Products. ......................................................................................... 19

18(a) Corrosion Products Lifted Off on a Carbon Tape and Imaged...................................... 20

18(b) EDAX of the corrosion products shown in Figure 18(a) .............................................. 20

19 High Magnification Photograph of the Corrosion Products and the Associated EDAX Pattern........................................................................................ 21

20 Low Magnification Image of the Ni-5\% P Coating on Yoke (NiARY1) ..................... 24

21 High Magnification Image of the Ni-5\% P Coating on Yoke (NiARY1) .................... 24

22 Low Magnification Image of the Ni-5\% P Coating on Yoke (NiARY2) ...................... 25

23 High Magnification Image of the Ni-5\% P Coating on Yoke (NiARY2) .................... 25

24 Low Magnification Image of the Ni-5\% P Coating on D-ring (NiARDR3) ................ 25

25 High Magnification Image of the Ni-5\% P Coating on D-ring (NiARDR3)................. 25

26(a) Low Magnification Micrograph of the White Residue on the WA14 Yoke Sample.... 29

26(b) EDAX Analysis of the Area in Figure 26(a) .............................................................. 29

27(a) High Magnification Micrograph of the White Residue on the WA14 Yoke Sample ... 30

27(b) EDAX Analysis of the Area in Figure 27(a).............................................................. 30

$28 \quad$ Hardness Measurements on WA14 D-ring ................................................................... 31

29 Hardness Values of the WA14 Yoke on the Shiny and Dull Surfaces ......................... 32

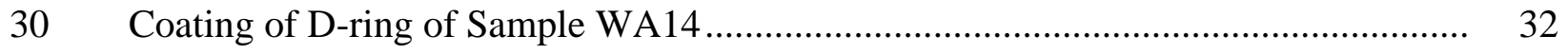

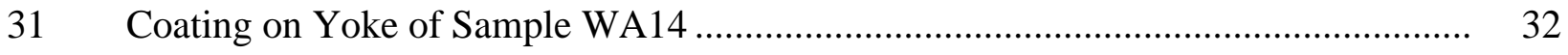

32 Higher Magnification of Coating on WA14 Yoke ....................................................... 33 


\section{FIGURES (Cont.)}

$33 \quad$ Hardness Values for 10P1 and 10P2 D-Ring Samples .................................................. 35

$34 \quad$ Hardness Values for 10P1 and 10P2 Yoke Samples .................................................... 35

$35 \quad$ Hardness Values for Aluminum-Coated Yoke Samples................................................ 37

$36 \quad$ Hardness value for D-ring 4915 ........................................................................... 38

37 Cross Sections of Aluminum-Coated Yoke Samples: (a) 4913, (b) 4914, (c) 4915, and (d) 4916 ........................................................................................... 39

38 Cross Section of Aluminum-Coated D-ring Samples............................................... 40

$39 \quad$ Aluminum (outer) and Nickel (inner) Coating Thicknesses for the Four Yoke Samples........................................................................................... 41

40 Aluminum (outer) and Nickel (inner) Coating Thicknesses for the Four D-ring Samples................................................................................................ 41

41 Damage Observed in the Coatings: (a) Delamination at the Nickel/Steel Interface and (b) Delamination at Nickel/Steel Interface and No Aluminum

\section{TABLES}

$1 \quad$ Hydrogen Analysis of As-Received Ni-5\% P Coated Yokes ........................................ 14

$2 \quad$ Hydrogen Analysis on Failed \#2 Corroded Yoke........................................................... 14

$3 \quad$ Hydrogen Analysis of \#6 Failed Yoke Sample............................................................. 15

4 Hydrogen Analysis on Corrosion Products Scraped Off from \#2 Failed Yoke and \#8 D-ring ......................................................................................................... 15

$5 \quad$ ICP-MS Analysis (wt.\%) on Various Steel and Corrosion Product Samples................ 23

$6 \quad$ Results from Ni Coating Thickness Measurements....................................................... 25

$7 \quad$ Metal Concentration (wt.\%) in White Residue of Sample W14................................... 31

$8 \quad$ Results for Coating Thickness Measurements for Samples 10P1 and 10P2 ................ 34

$9 \quad$ Hydrogen Analysis Results for Samples 10P1 and 10P2 ……................................... 36 


\section{ABBREVIATIONS}

$\begin{array}{ll}\text { ANL } & \text { Argonne National Laboratory } \\ \text { BJC } & \text { Bechtel Jacobs Company } \\ \text { D\&D } & \text { Decontamination and Decommissioning } \\ \text { DOE } & \text { Department of Energy } \\ \text { EDAX } & \text { Energy Dispersive X-Ray Analysis } \\ \text { ETTP } & \text { East Tennessee Technology Park } \\ \text { HLL } & \text { Horizontal Life Lines } \\ \text { ICP-MS } & \text { Induction Coupled Plasma - Mass Spectroscopy } \\ \text { SEM } & \text { Scanning Electron Microscope }\end{array}$




\section{EXECUTIVE SUMMARY}

The U.S. Department of Energy and its contractor, Bechtel Jacobs Company(BJC), are undertaking a major effort to clean up the former gaseous diffusion facility (K-25) located in Oak Ridge, TN. The decontamination and decommissioning activities require systematic removal of contaminated equipment and machinery followed by demolition of the buildings.

As part of the cleanup activities, a beam clamp, used for horizontal life lines (HLLs) for fall protection, was discovered to be fractured during routine inspection. The beam clamp (yoke and D-ring) was a component in the HLL system purchased from Reliance Industries LLC. Specifically, the U-shaped stainless steel yoke of the beam clamp failed in a brittle mode at under less than $10 \%$ of the rated design capacity of $14,500 \mathrm{lb}$. The beam clamp had been in service for approximately 16 months.

Bechtel Jacobs approached Argonne National Laboratory to assist in identifying the root cause of the failure of the beam clamp. The objectives of this study were to (1) review the prior reports and documents on the subject, (2) understand the possible failure mechanism(s) that resulted in the failed beam clamp components, (3) recommend approaches to mitigate the failure mechanism(s), and (4) evaluate the modified beam clamp assemblies.

Energy dispersive x-ray analysis and chemical analysis of the corrosion products on the failed yoke and white residue on an in-service yoke indicated the presence of zinc, sulfur, and calcium. Analysis of rainwater in the complex, as conducted by BJC, indicated the presence of sulfur and calcium. It was concluded that, as a result of galvanic corrosion, zinc from the galvanized components of the beam clamp assembly (D-ring) migrated to the corroded region in the presence of the rainwater. Under mechanical stress, the corrosion process would have accelerated, resulting in the catastrophic failure of the yoke.

As suggested by Bechtel Jacobs personnel, hydrogen embrittlement as a consequence of corrosion was also explored as a failure mechanism. Corroded and failed yoke samples had hydrogen concentrations of 20-60 ppm. However, the hydrogen content reduced to 4-11 ppm (similar to baseline as-received yoke samples) when the corrosion products were polished off. The hydrogen content in the scraped off corrosion product powders was $>7000 \mathrm{ppm}$. These results indicate that hydrogen is primarily present in the corrosion products and not in the underlying steel.

Rockwell hardness values on the corroded yoke and $\mathrm{D}$-rings were $\mathrm{R}_{\mathrm{C}} \sim 41$-46. It was recommended to the beam clamp manufacturer that the beam clamp components be annealed to reduce the hardness values so that they are less susceptible to brittle failure. Upon annealing, hardness values of the beam clamp components reduced to $\mathrm{R}_{\mathrm{C}} \sim 25$.

Several strategies were recommended and put in place to mitigate failure of the beam clamp components: (a) maintain hardness levels of both yokes and D-rings at $R_{C}<35$, (b) coat the yoke and D-rings with a dual coating of nickel (with $10 \%$ phosphorus) to delay corrosion and 
aluminum to prevent galvanic corrosion since it is more anodic to zinc, and (c) optimize coating thicknesses for nickel and aluminum while maintaining the physical integrity of the coatings.

Evaluation of the Al- and Ni-coated yoke and D-ring specimens indicated they appear to have met the recommendations. Average hardness values of the dual-coated yokes were $\mathrm{R}_{\mathrm{C}} \sim 25-35$. Hardness values of dual-coated $\mathrm{D}$-ring were $\mathrm{R}_{\mathrm{C}} \sim 32$. Measured average coating thicknesses for the aluminum and nickel coatings for yoke samples were $22 \mu \mathrm{m}$ ( 0.9 mils) and $80 \mu \mathrm{m}$ (3 mils), respectively. The D-rings also showed similar coating thicknesses. Microscopic examination showed that the aluminum coating was well bonded to the underlying nickel coating. Some observed damage was believed to be an artifact of the cutting-and-polishing steps during sample preparation for microscopy. 


\section{INTRODUCTION}

Currently, the U.S. Department of Energy (DOE) and its contractor, Bechtel Jacobs Company (BJC), are undertaking a major effort to clean up the former gaseous diffusion facility (K-25) located in Oak Ridge, TN. The decontamination and decommissioning (D\&D) activities require systematic removal of contaminated equipment and machinery followed by demolition of the buildings.

As part of the cleanup activities, a beam clamp, used for horizontal life lines (HLLs) for fall protection, was discovered (August 10, 2009) to be fractured during routine inspection at the K-25 building pipe gallery at the East Tennessee Technology Park (ETTP). The beam clamp (part \# 3093) was a component in the HLL system purchased from Reliance Industries LLC. Specifically, the U-shaped stainless steel yoke of the beam clamp had undergone a brittle-type failure (fragmented) under less than $10 \%$ of the rated design capacity of $14,500 \mathrm{lb}$. The beam clamp had been in service for 16 months.

Bechtel Jacobs, who is managing the D\&D activities at ETTP, has approached Argonne National Laboratory (ANL) to assist them in identifying the root cause of the failure of the beam clamp and also in evaluating the new modified beam clamps that Reliance Industries has supplied. In this regard, ANL and BJC (Mr. Abdul Dada and Mr. Tim Carty) had a meeting on September 22, 2009, at ANL to identify the specific tasks to be conducted by ANL, and those are listed below:

- Review current documentation provided by BJC

- Complete chemical analysis of the D-ring and yokes

- Identify the corrosion mechanisms

- Measure hardness

- Determine nickel plating coating thickness

- Review Reliance Industries beam clamp inspection plan 


\section{REVIEW OF DOCUMENTS PROVIDED BY BJC}

Bechtel Jacobs provided several documents related to the failed yoke at the K25 plant at Oak Ridge. Some of the documents provided are listed:

- $\quad$ Pictures of failed yoke and corroded beam clamps

- Report on “Assessment of Oak Ridge Yoke Failure,” prepared by Dr. George Krauss, Metallurgical Consultant at Colorado School of Mines

- Report entitled “Preliminary Evaluation of Beam Clamp Yoke Failure,” prepared by Structural Integrity Associates

- Email communication between Mr. Timothy Knaub and Mr. Abdul Dada related to beam clamp failure

- Materials Safety Data Sheet for gypsum wall board panels

- Results of analysis of rain-water samples from inside and outside of the building

- Inspection Instructions 3093 HLL anchor clamps from Reliance Industries

These documents were reviewed by ANL to understand the various issues related to yoke failure. 


\section{SAMPLE DESCRIPTION}

Bechtel Jacobs supplied ANL with the following samples for initial analysis:

1. Two sets of corroded and failed yokes. Figures 1 and 2 show the failed yokes. For reference, these samples were labeled as 2YC and 6YC, and this identification is used for the rest of the report. Figure 3 shows a high magnification image of the corroded sample 6YC. Yoke samples are 420 stainless steel.

2. Five sets of used beam clamp assemblies. These samples showed varying degrees of corrosion. These samples were referred to as the "K25 five."

Figure 4 shows the entire beam clamp assembly for one of the five, which was numbered as \#8. The D-rings were zinc plated. The D-ring samples are 4140 steel.

3. Five new pairs of yoke and D-rings. These samples were supplied by Reliance Industries and were coated with nickel (5\% phosphorus). This coating was specified by the vendor to be 1 to 1.5 mils ( 25 to 38 microns) thick. Figure 5 shows the five sets of yoke/D-ring samples received. These yokes and D-ring samples were designated as NiARY1 to NiARY5 and NiARDR1 to NiARDR5, respectively. 


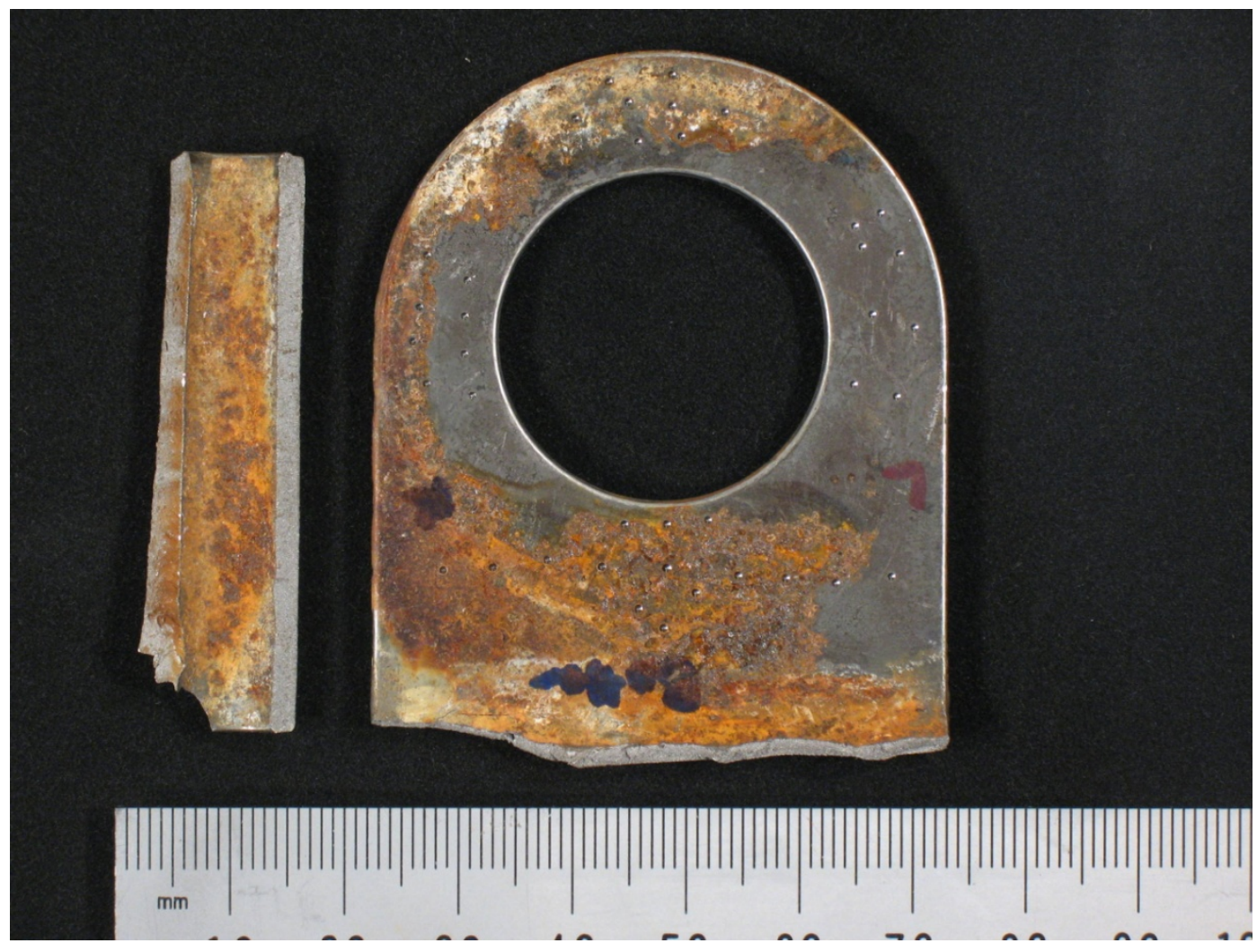

FIGURE 1 Photograph of Corroded and Failed Yoke Sample \#6YC.

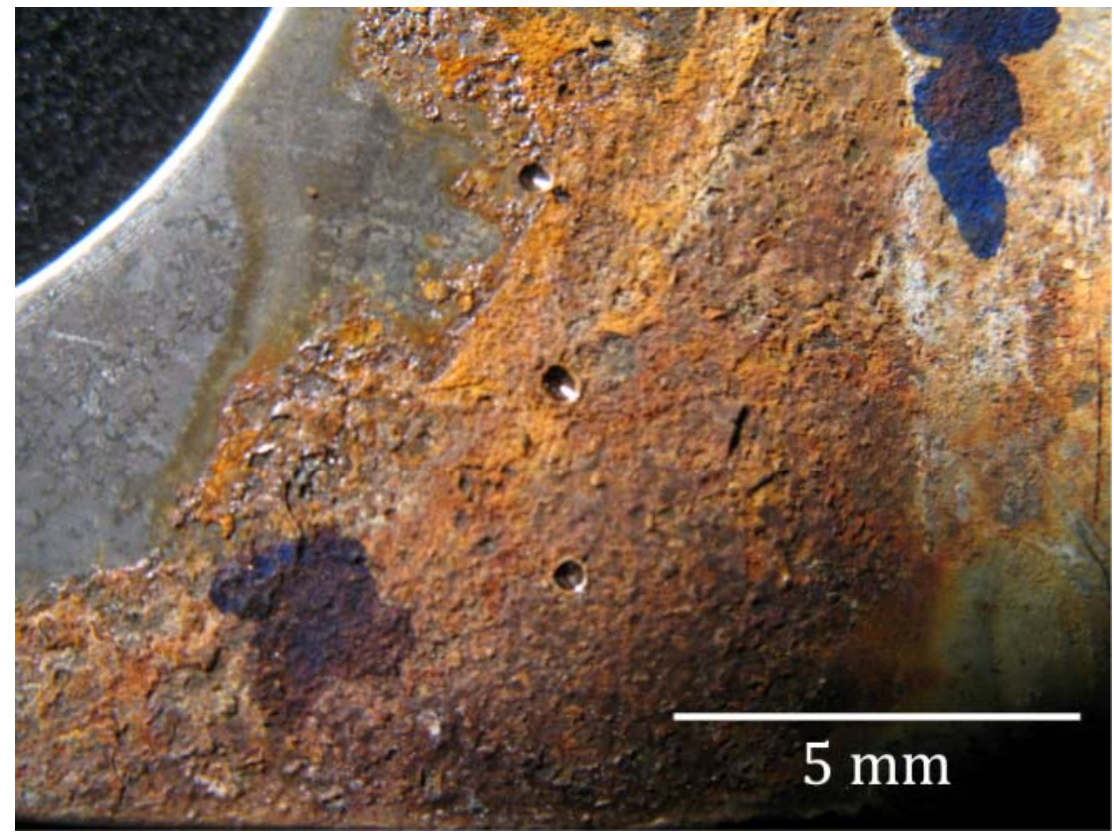

FIGURE 2 Higher Magnification of the Corroded and Failed Yoke \#6YC. Three indents seen in the photograph are from hardness tests. 


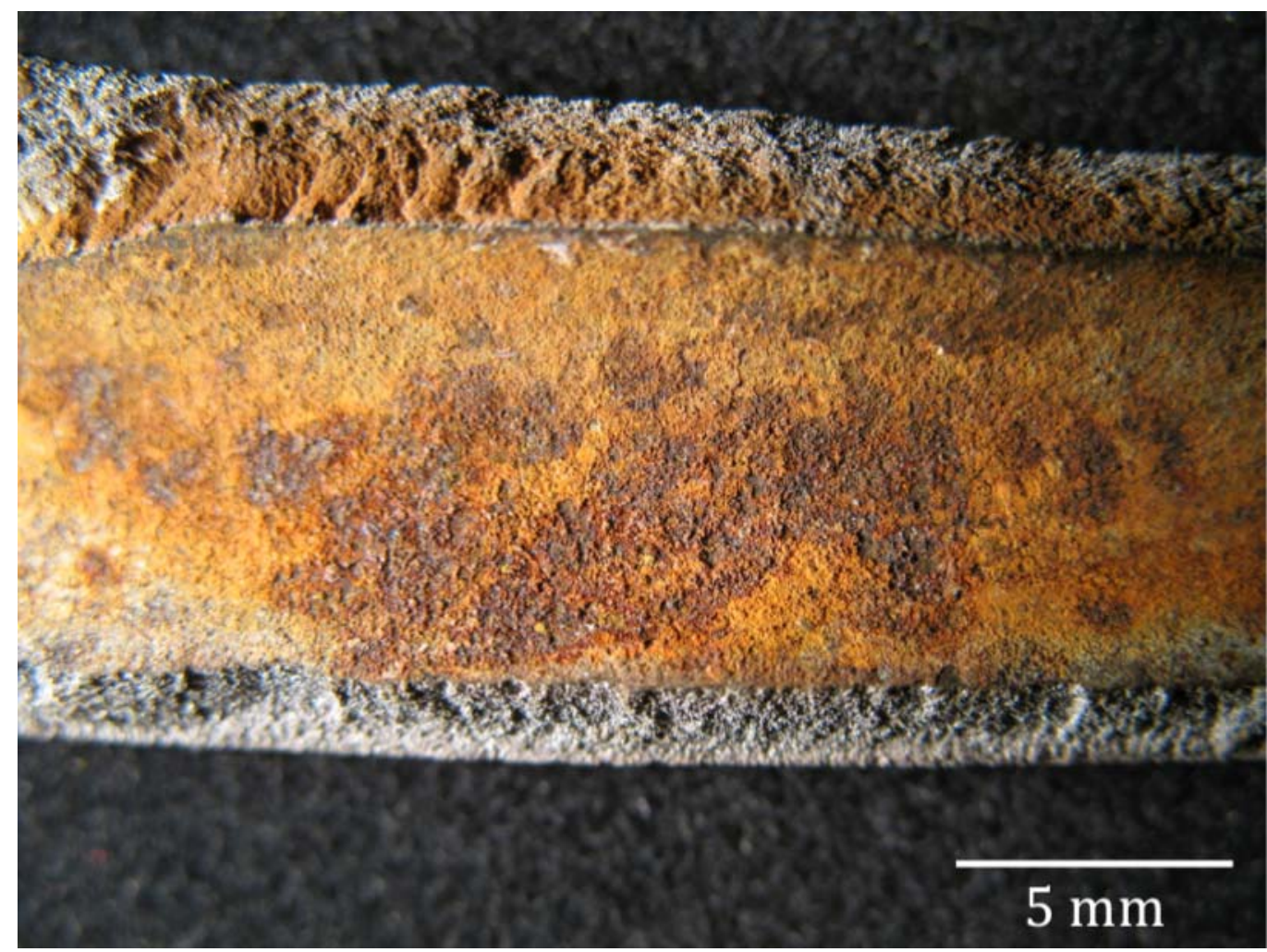

FIGURE 3 High Magnification Picture of Fracture Surface of \#6YC Sliver as shown in Figure 1.

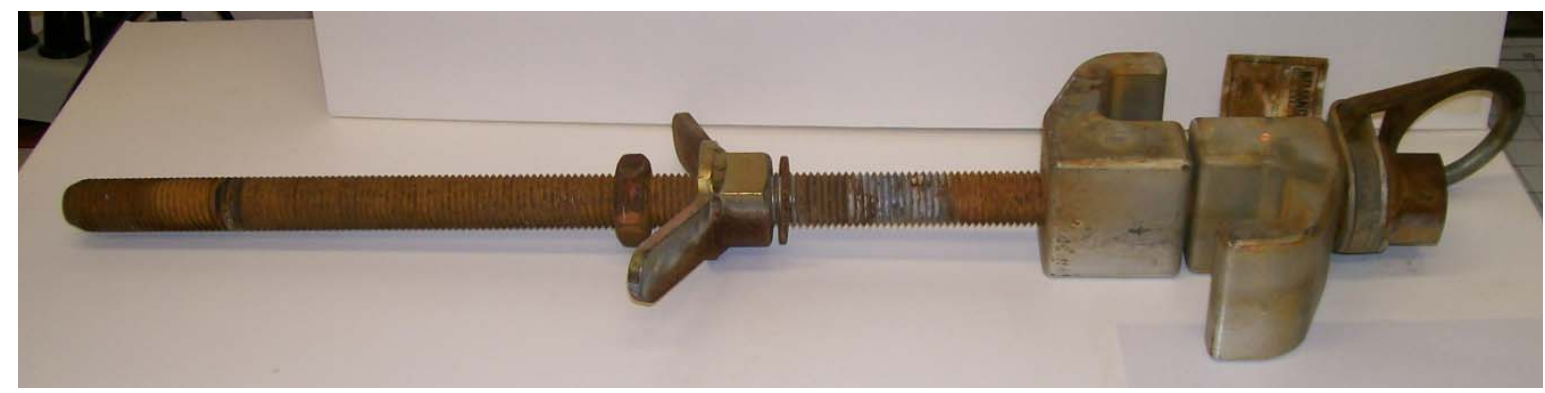

FIGURE 4 One of "K25 five” Beam Clamp Assemblies Received by ANL. Labeled as Sample \#8. 


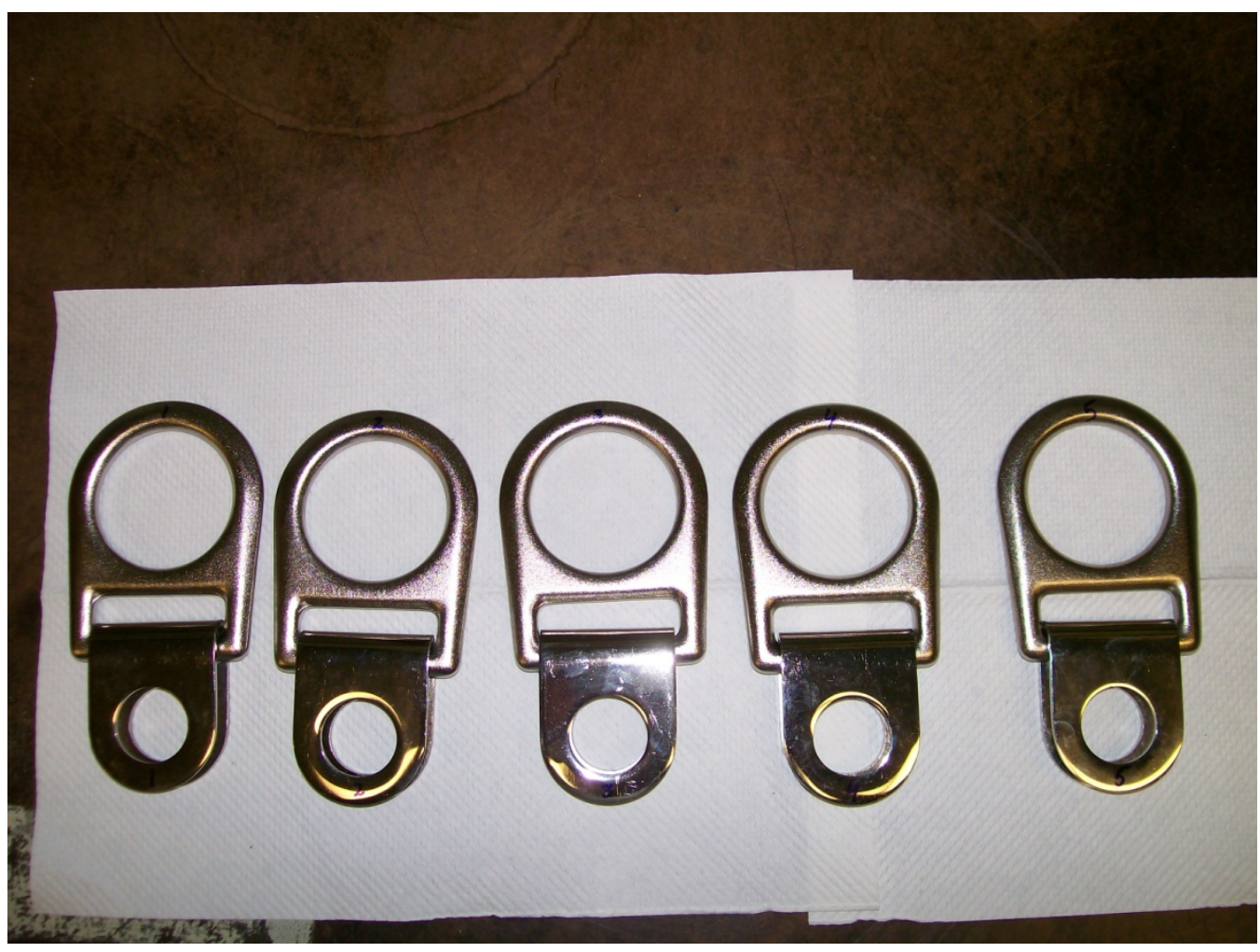

FIGURE 5 Five As-Received Ni-5\% P Coated Yoke/D-ring Assemblies. 


\section{HARDNESS MEASUREMENTS}

\subsection{SAMPLES}

Assuming that hydrogen embrittlement is the cause of the drastic drop in the ductility of the steel, annealing of the steel and reduction of the hardness may possibly mitigate the embrittlement. Thus, BJC wanted ANL to determine the hardness (Rockwell C) on two D-ring and yoke samples, each of which had been annealed. Note that these samples, provided by Reliance Industries, were coated with nickel-5\% phosphorus alloy. Hardness values were compared with those of the un-annealed samples (corroded samples of yoke and D-rings) to compare the effect of annealing.

\subsection{HARDNESS MEASUREMENTS}

Rockwell C hardness measurements were made on both as-received and serviced yoke and D-ring samples. The hardness of the D-ring and yoke samples was tested with a Rockwell Hardness Tester (Wilson Mechanical Instruments, New York, NY) on the Rockwell C scale with a $150 \mathrm{~kg}$ load. The hardness indenter was calibrated with a specimen of known hardness ( $25.3 \pm 1.0$ HRC, F. F. Gilmore Co) prior to each testing session. The samples were preloaded before the indenter was lowered into the sample. It was held there for about 30 seconds until equilibrated, then removed to display the hardness value on the gauge.

Prior to hardness testing, the yoke samples were cut such that each flat side was removed from the curved middle section for ease of testing. The hardness of both of these flat sides was then tested at least five times in each of four locations on the surface of both the shiny and dull sides (Figure 6). The D-ring was tested at least 10 times in each of two locations on both the top and bottom of the sample (see Figure 7). Photographs of the samples with the indents visible are shown in Figure 8 (NiARY1 yoke), Figure 9 (NiARDR1), Figure 10 (2YC yoke), and Figure 11 (2DRC).

Average hardness values were determined for each location tested in each sample as well as for the sample as a whole based on all measurements performed. In this report overall average hardness is only reported. The average hardness results for these four samples are shown in Figures 12-14. The results indicate that for the D-rings, the hardness values for the as-received and corroded samples are quite similar, as expected. This is because the as-received D-rings were not annealed. The yokes, however, show a significant decrease in hardness for the as-received samples as compared to the corroded samples. This decrease was both on the shiny and dull sides. In both the as-received and corroded yoke samples, the hardness was higher on the dull side than the shiny side, probably due to differences in surface finishes. For the as-received yoke samples, the lower hardness values seen for the yokes as compared to the D-rings are due to the annealing step performed on the as-received Ni-coated yokes. 


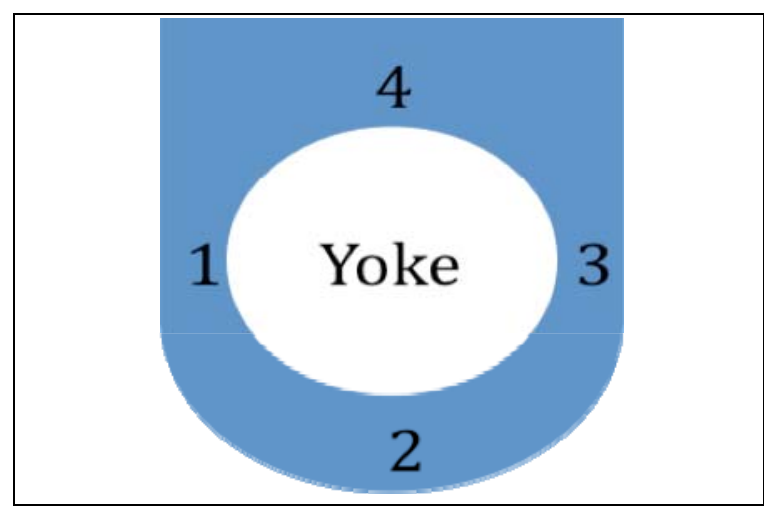

FIGURE 6 Schematic of Cut Yoke Sample for Hardness Measurements. Numbers indicate hardness measurement locations.

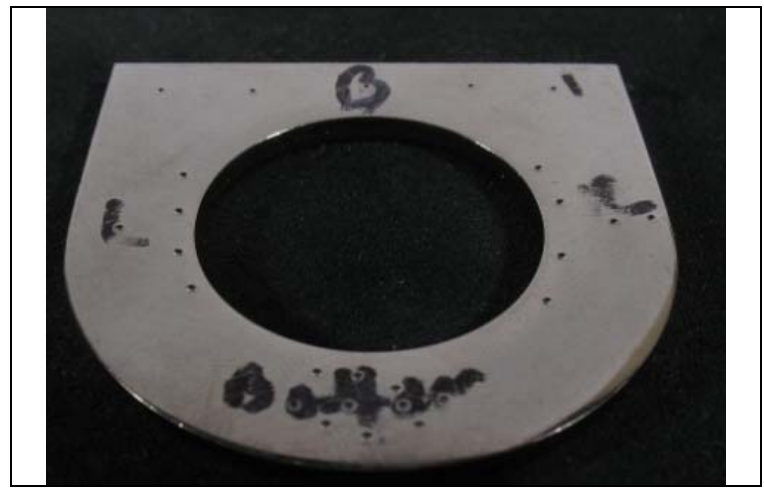

FIGURE 8 As-Received Yoke Sample NiARY1 with Indents.

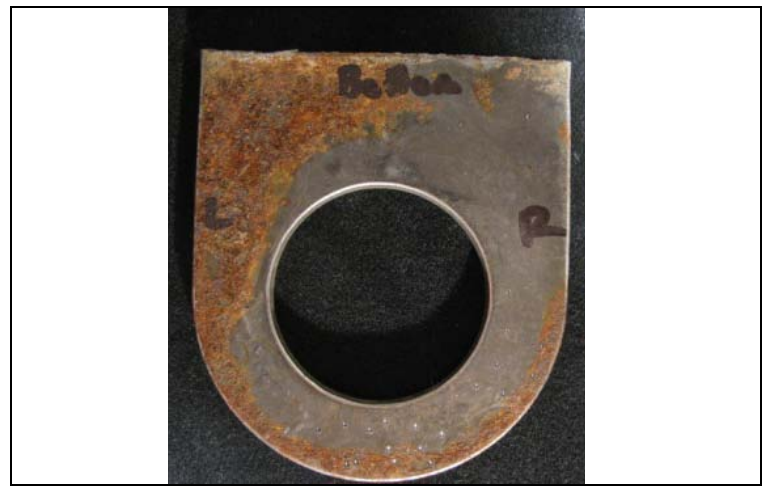

FIGURE 10 Corroded Yoke Sample 2YC with Indents.

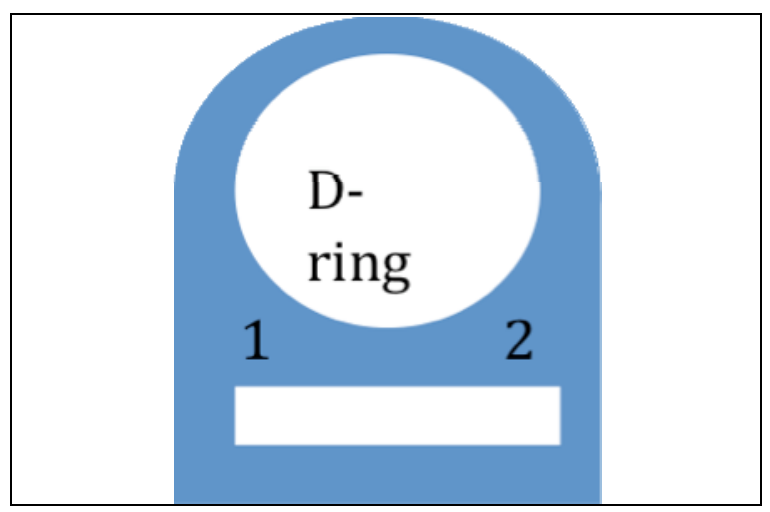

FIGURE 7 Schematic of D-ring Sample for Hardness Measurements. Numbers indicate hardness measurement locations.

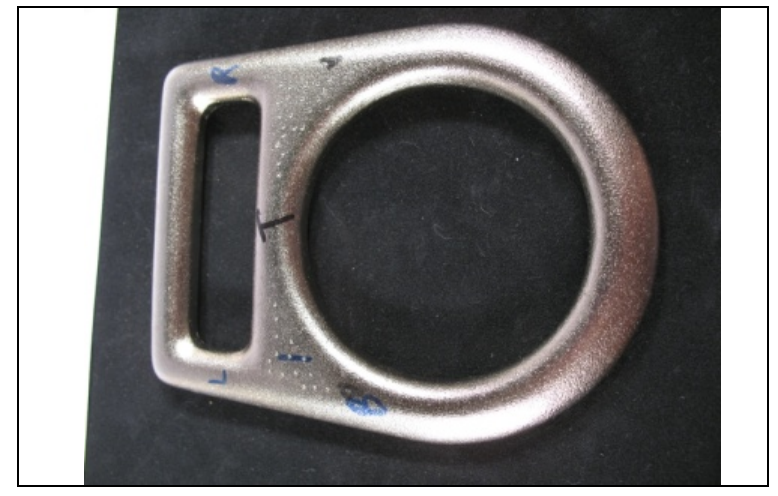

FIGURE 9 As-Received D-ring Sample NiARDR1 with Indents.

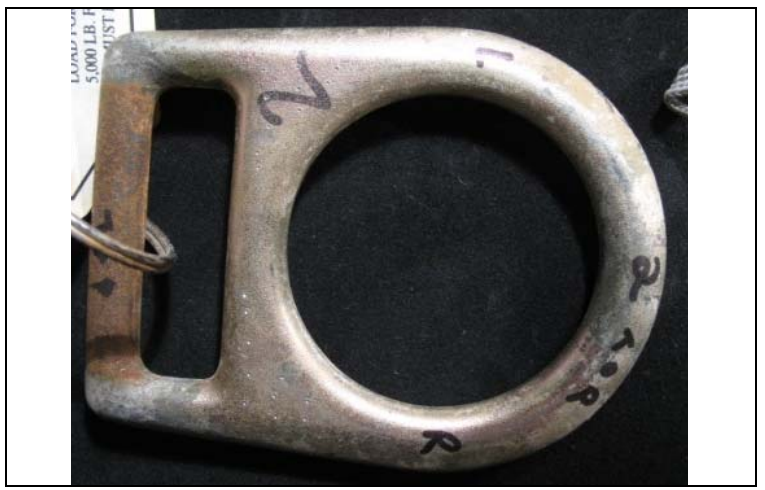

FIGURE 11 Corroded D-ring Sample 2DRC with Indents. 


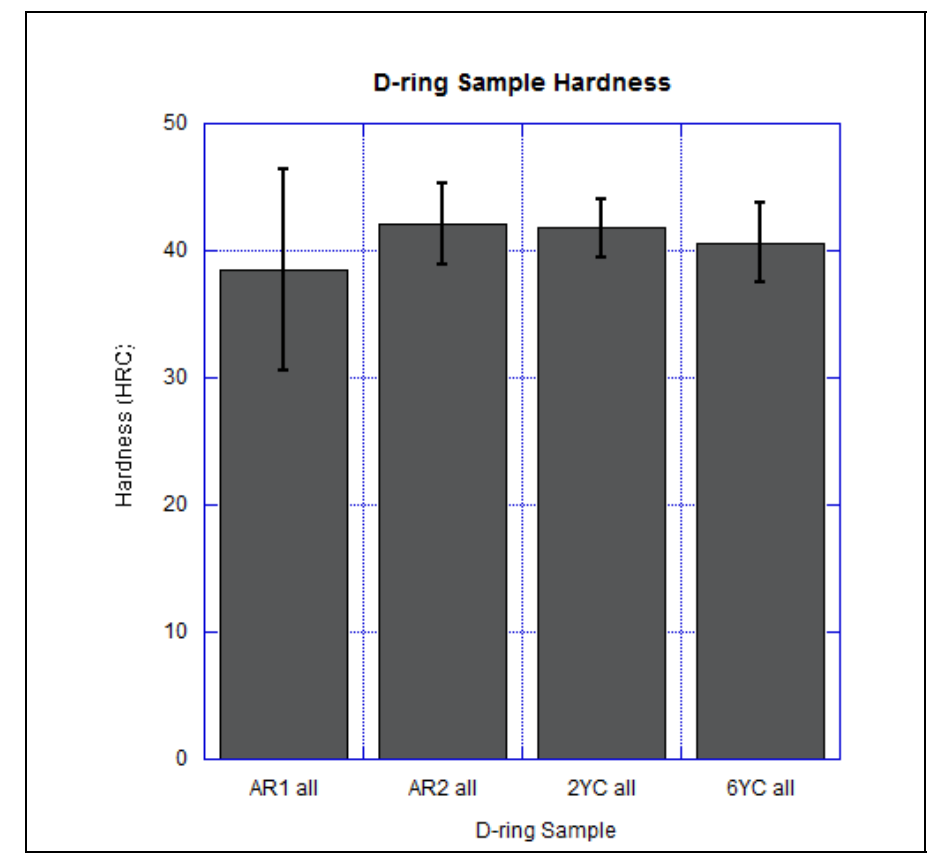

FIGURE 12 Hardness Values of As-Received and Corroded D-rings.

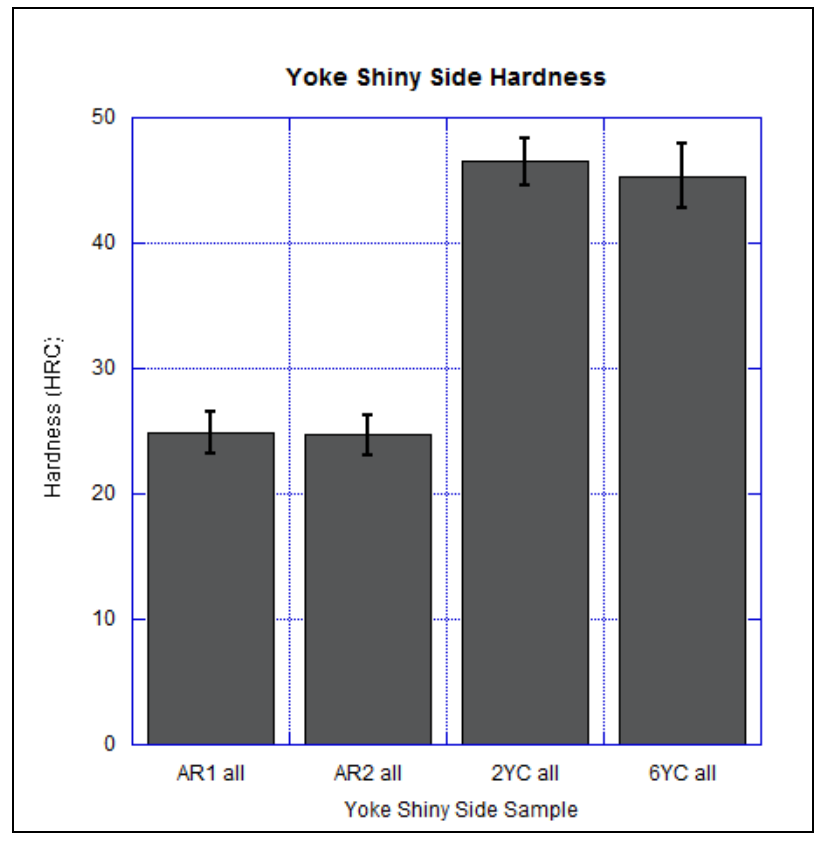

FIGURE 13 Hardness Values of As-Received and Corroded Yokes on the Shiny Side.

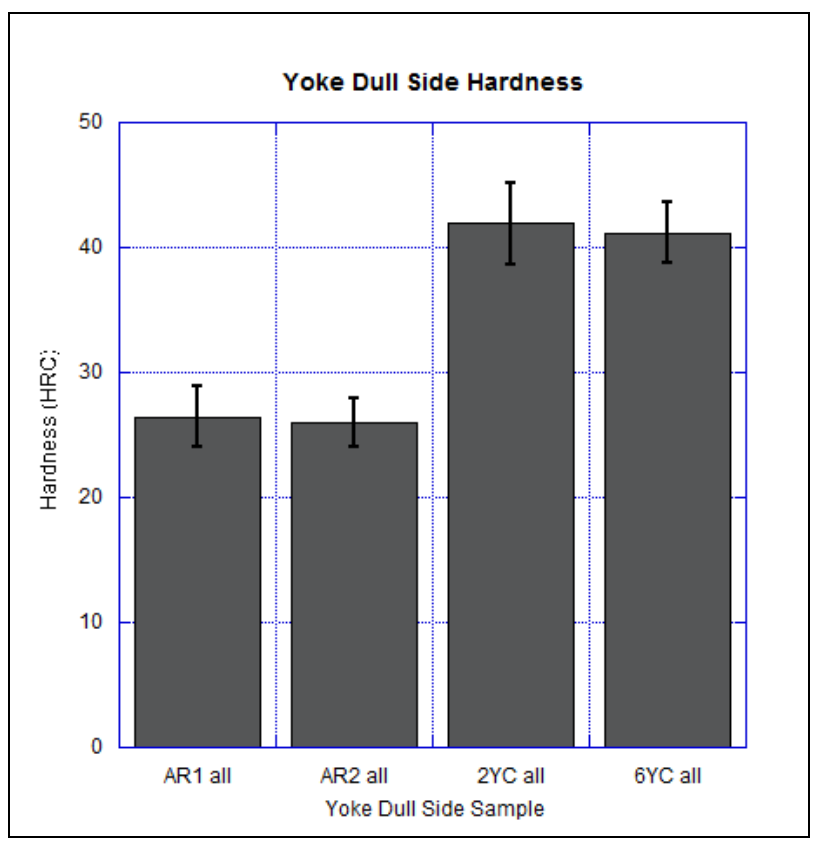

FIGURE 14 Hardness Values of As-Received and Corroded Yokes on the Dull Side. 


\subsection{SUMMARY}

- The corroded yoke showed Rockwell C hardness values of $R_{C} \sim 40-42$.

- $\quad$ Corroded D-ring samples showed Rockwell C hardness values of $\mathrm{R}_{\mathrm{C}} \sim$ 41-46.

- Annealing of the Ni-coated (5\% P) yoke samples resulted in a decrease in hardness values to $\mathrm{R}_{\mathrm{C}} \sim 25$. 


\section{HYDROGEN ANALYSIS OF STEEL SAMPLES}

Based on the discussions with BJC personnel and email report from Mr. Tim Knaub [1], hydrogen embrittlement, resulting from corrosion, appears to be the cause of the failure of the yokes. To investigate this further, it was decided to measure the hydrogen content in the failed yokes and compare the results with those of the uncorroded samples.

\subsection{HYDROGEN DETERMINATION}

Hydrogen content in the baseline as-received steel samples, corroded samples, and corrosion products was determined with a hydrogen analyzer (Model RH-404, LECO). This microprocessor-based instrument determines hydrogen content in ferrous and nonferrous metals in an electrode furnace. Before analysis, the instrument is calibrated by a standard method that involves analyzing several known standard samples. After calibration, analysis begins by placing a graphite crucible containing tin flux on the lower electrode. After the electrode furnace is closed, high current is passed through the crucible, generating high temperature that drives off or outgases impurities trapped in the tin flux and graphite crucible. After a brief cooling period and analysis delays, the furnace is switched $\mathrm{ON}$, and the sample is dropped into the crucible. Hydrogen is separated from other gases by a series of absorption/molecular sieves and is detected by thermal conductivity.

\subsection{SAMPLES}

Hydrogen analyses were conducted on the as-received nickel-coated (5\% P) yoke and D-ring samples and the corroded yoke samples. Further, for the corroded yoke samples, three sample conditions were investigated: failed yoke sample with corrosion products on the surface, failed yoke sample with corrosion products polished off, and corrosion products itself.

\subsection{RESULTS}

Tables 1-4 present the hydrogen analysis results given as parts per million (ppm) of the total sample analyzed. Table 1 shows the hydrogen content in the as-received $\mathrm{Ni}-5 \% \mathrm{P}$ coated yoke samples. Several samples from two yokes (\#1 and \#2) were evaluated, and the typical values were 5-8 ppm of hydrogen. However, there was one sample (NiARY2) that showed elevated levels of hydrogen. The reason for the high value is not clear. One possibility could be that some trapped hydrogen may have been in the samples as a result of the Ni plating process.

Table 2 shows the results of the \#2 failed yoke. For the samples that were evaluated with the corrosion products, the hydrogen contents were 21-40 ppm. However, for the sample for which the corrosion layer was polished away, the hydrogen concentration reduced to $4.4 \mathrm{ppm}$. 
TABLE 1 Hydrogen Analysis of As-Received Ni-5\% P Coated Yokes

\begin{tabular}{lccc}
\hline Sample ID & Sample Description & $\begin{array}{c}\mathrm{H}_{2} \text { Content } \\
(\mathrm{ppm})\end{array}$ & $\begin{array}{c}\text { Sample Obtained } \\
\text { From }\end{array}$ \\
\hline NiAR Y-1 & Ni-5\% P coated as-received yoke & 7.2 & Yoke \# 1 \\
NiAR Y-2 & Ni-5\% P coated as-received yoke & 46.9 & Yoke \# 2 \\
NiAR 2A & Ni-5\% P coated as-received yoke & 5.7 & Yoke \# 2 \\
NiAR 2B & Ni-5\% P-coated as-received yoke & 5.7 & Yoke \# 2 \\
NiAR 2C & Ni-5\% P coated as-received yoke & 7.3 & Yoke \# 2 \\
NiAR 2A & Ni-5\% P coated as-received yoke & 5.8 & Yoke \# 2 \\
\hline
\end{tabular}

TABLE 2 Hydrogen Analysis on Failed \#2 Corroded Yoke

\begin{tabular}{lccc}
\hline Sample ID & Sample Description & $\begin{array}{c}\mathrm{H}_{2} \text { Content } \\
(\mathrm{ppm})\end{array}$ & $\begin{array}{c}\text { Sample Obtained } \\
\text { From }\end{array}$ \\
\hline 2YC-1 & $\begin{array}{c}\text { Corroded yoke \#2 } \\
\text { unpolished }\end{array}$ & 39.5 & $\begin{array}{c}\text { Yoke sample } \\
\text { labeled 2 }\end{array}$ \\
2YC-2 & $\begin{array}{c}\text { Corroded yoke \#2 } \\
\text { unpolished }\end{array}$ & 23.1 & $\begin{array}{c}\text { Yoke sample } \\
\text { labeled 2 }\end{array}$ \\
2YC-3 & $\begin{array}{c}\text { Corroded yoke \#2 } \\
\text { unpolished } \\
\text { 2YC-1UP }\end{array}$ & 29.5 & $\begin{array}{c}\text { Yoke sample } \\
\text { labeled 2 }\end{array}$ \\
2YC-P & $\begin{array}{c}\text { Corroded yoke unpolished } \\
\text { Corroded yoke, corrosion products } \\
\text { polished }\end{array}$ & 21.6 & Yoke \# 2 \\
\hline
\end{tabular}

Table 3 shows the results of the \#6 failed yoke sample. Here again, analysis was carried out on samples with and without corrosion layers. Results were quite similar to those obtained for the \#2 failed yoke. Unpolished samples showed hydrogen levels of 40-60 ppm. In contrast, polished samples showed hydrogen concentrations between 4 and 11 ppm.

Finally, Table 4 tabulates the results from the corrosion products scraped off from the corroded \#2 failed yoke and D-ring \#8 samples. The hydrogen concentrations were >7,500 ppm for both the corrosion products, indicating that hydrogen is bound in the corrosion products. 
TABLE 3 Hydrogen Analysis of \#6 Failed Yoke Sample

\begin{tabular}{lccc}
\hline Sample ID & Sample Description & $\begin{array}{c}\mathrm{H}_{2} \text { Content } \\
(\mathrm{ppm})\end{array}$ & $\begin{array}{c}\text { Sample Obtained } \\
\text { From }\end{array}$ \\
\hline 6YC-UP-1 & $\begin{array}{c}\text { Corroded yoke } \\
\text { unpolished }\end{array}$ & 42.4 & Yoke \# 6 \\
6YC-UP-2 & $\begin{array}{c}\text { Corroded yoke } \\
\text { unpolished } \\
\text { 6YC-P-1 }\end{array}$ & 60.7 & Yoke \# 6 \\
Corroded yoke & 11.67 & Yoke \# 6 \\
polished & & Yoke \# 6 \\
6YC-P-3 & $\begin{array}{c}\text { Corroded yoke } \\
\text { polished }\end{array}$ & 8.62 & Yoke \# 6 \\
& Corroded yoke \\
polished & 4.4 & \\
\hline
\end{tabular}

TABLE 4 Hydrogen Analysis on Corrosion Products Scraped Off from \#2 Failed Yoke and \#8 D-ring

\begin{tabular}{cccc}
\hline Sample ID & Sample Description & $\begin{array}{c}\mathrm{H}_{2} \text { Content } \\
\text { (ppm) }\end{array}$ & $\begin{array}{c}\text { Sample Obtained } \\
\text { From }\end{array}$ \\
\hline 2YCP-powder & $\begin{array}{c}\text { Scraped off corrosion products } \\
\text { from failed yoke \#2 }\end{array}$ & 7,503 & Yoke \#2 \\
8DRCP-powder & $\begin{array}{c}\text { Scraped off corrosion products } \\
\text { from D-ring \#8 from the K25 five }\end{array}$ & 7,607 & $\begin{array}{c}\text { D-ring \# 8 from } \\
\text { K25 five }\end{array}$ \\
\hline
\end{tabular}




\subsection{SUMMARY}

- As-received Ni-5\% P coated yoke samples showed hydrogen concentrations of 5-8 ppm.

- Corroded and failed yoke samples (\#2 and \#6) had hydrogen concentrations of 20-40 ppm and 40-60 ppm, respectively. These levels were reduced significantly (to 4-11 ppm) when the corrosion products were polished off.

- The high hydrogen concentration in the corrosion products indicates that hydrogen is primarily present in the corrosion products and not in the underlying steel. 


\section{ANAL YSES OF FAILED YOKE}

Scanning electron microscopy (SEM) and energy dispersive x-ray analysis (EDAX) were conducted on one section of the failed \#2YC yoke. The purpose of these analyses was to determine the fracture morphology of the failed samples and to investigate the structure of the corrosion products and its elemental composition.

\subsection{RESULTS}

Figure 15(a) shows the fracture surface of the failed yoke (\#2YC). There was no corrosion product observed in this region. Higher magnification shows intergranular fracture morphology normally associated with brittle failure. Figure 16(a) is a higher magnification of the same area as in Figure 15(b). Figure 16(b) shows the EDAX spectrum of the field of view of Figure 16(a). Clearly, the main components are detectable, such as iron and chromium.

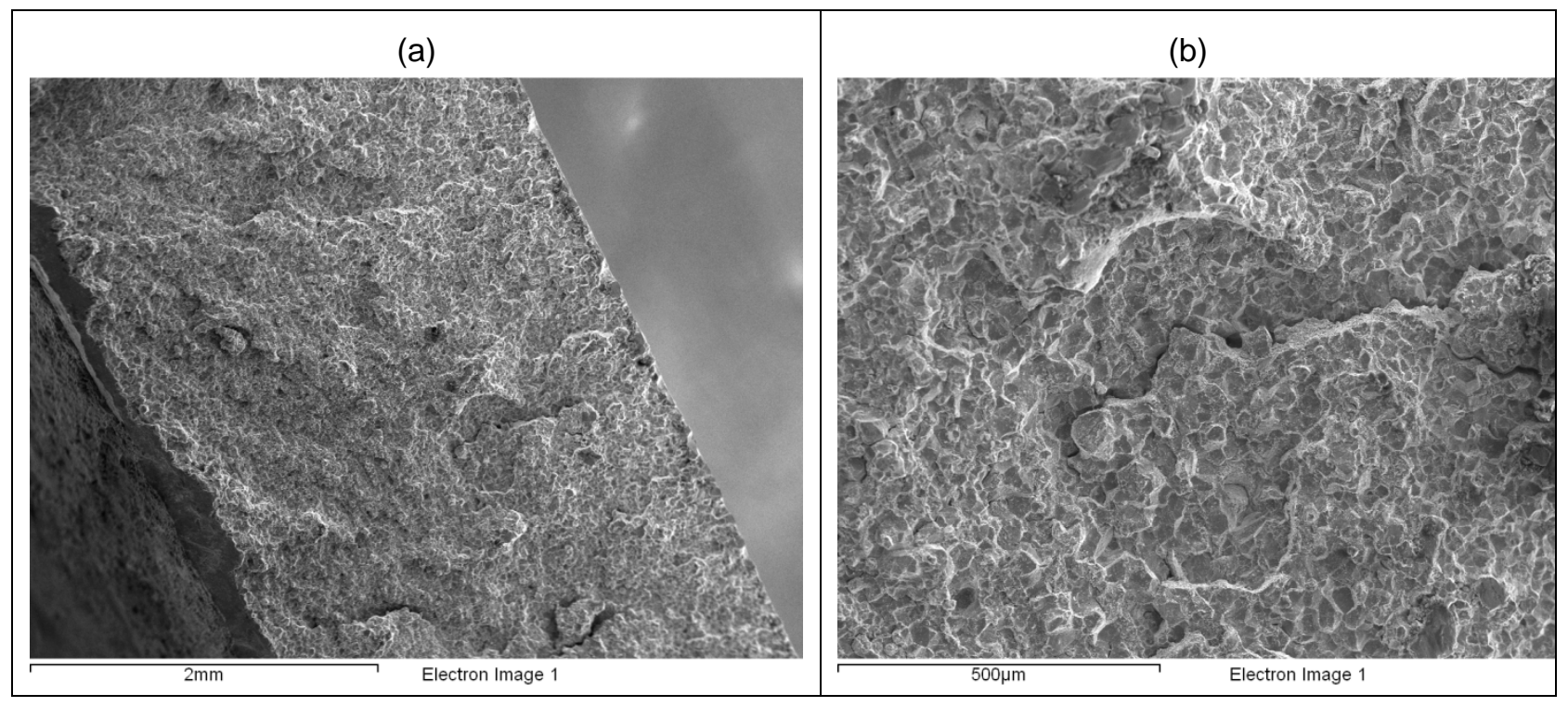

FIGURE 15(a) Fractured Edge from Small Piece of Steel. This was the cleanest fractured surface. There was no apparent presence of corrosion.
FIGURE 15(b) Higher Magnification of Area in Figure 15(a). 
(a)

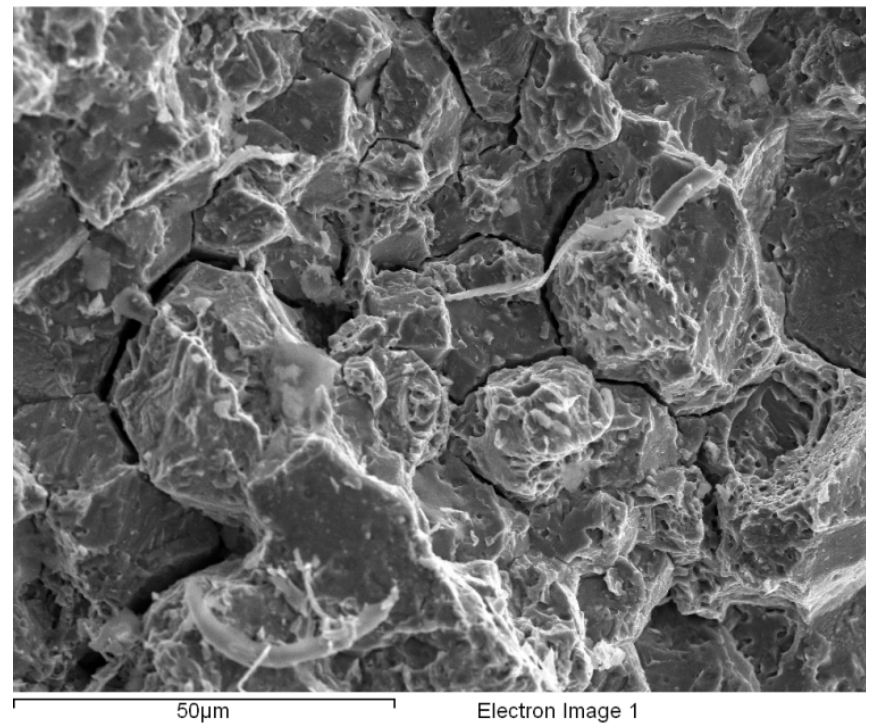

(b)

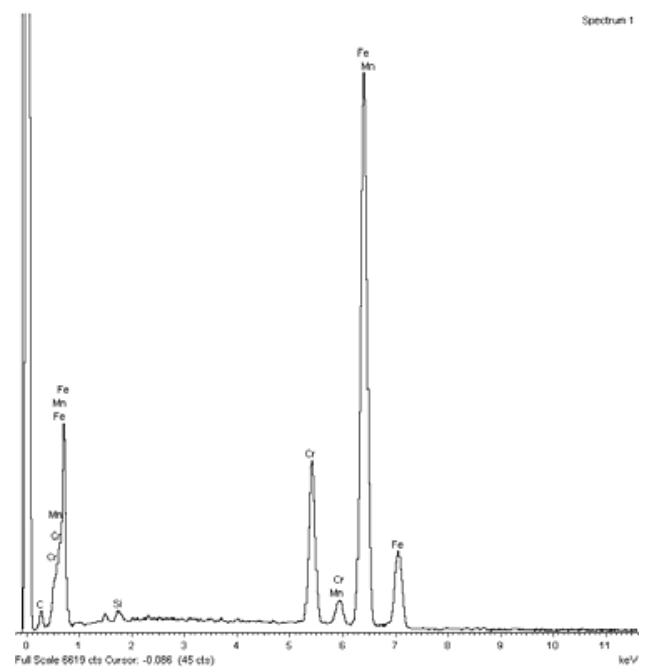

FIGURE 16(b) EDAX Analysis of the Area Shown in Figure 16(a).
FIGURE 16(a) Higher Magnification of Area in Figure 15(b).

The next SEM image was taken from an area that had some corrosion products deposited on the fracture surface. Successive higher magnifications of the area are shown in Figures 17(a-c). Figure 17(c) clearly shows the corrosion products. The EDAX conducted on the area is shown in Figure 17(d). Apart from the steel constituents such as those observed in Figure 16(b), zinc and sulfur were detected as well. Zinc probably migrated from the galvanized components of the beam clamp assembly. Similar results indicating the presence of zinc and sulfur were also obtained in another area where corrosion product was present.

To ensure that zinc and sulfur were indeed in the corrosion products, some of the corrosion products were picked off the steel surface by using tape, and SEM was conducted. Results are shown in Figure 18(a) and Figure 18(b). Again, the EDAX spectrum indicates that the zinc and sulfur are in the corrosion products. Finally, a higher magnification of the corrosion products itself shows a needle-like structure, as evident in Figure 19 (top), and its corresponding EDAX spectrum is shown in Figure 19 (bottom). Bechtel Jacobs provided ANL with the analysis [2] of the rainwater from the K-25 building area, and the results showed high concentrations of sulfur (in sulfate form) and calcium. Bechtel Jacobs suggested that the calcium resulted from the gypsum board and concrete used in the building. 


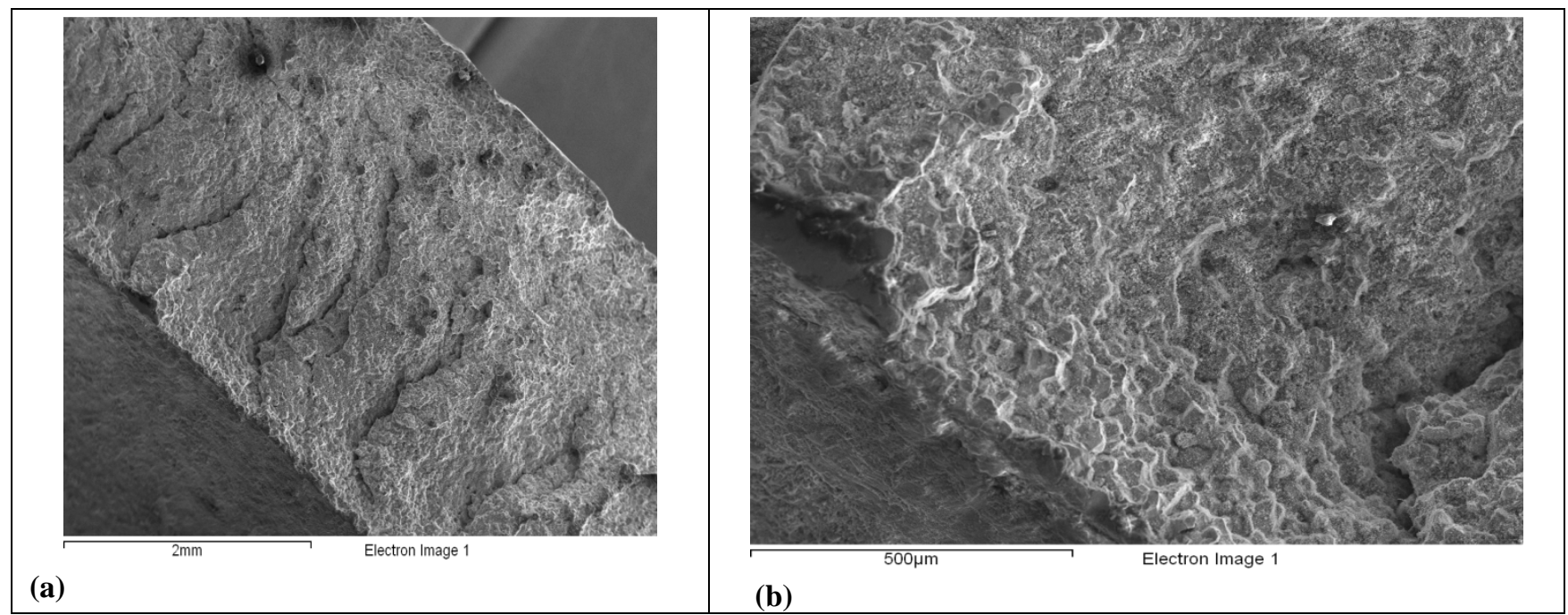

FIGURE 17(a) Fracture Surface of 2YC, with Area of Corrosion.

FIGURE 17(b) Higher Magnification of the Area Shown in Figure 17(a).

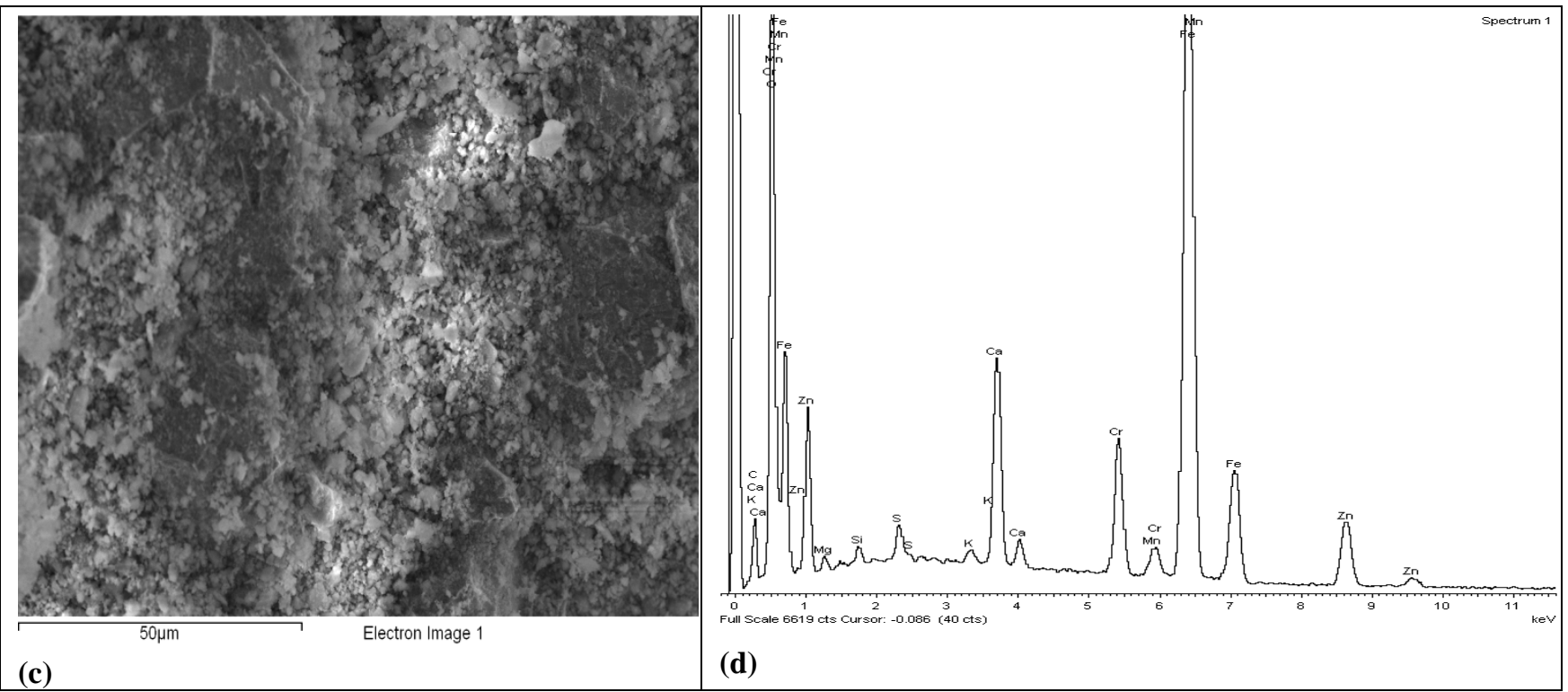

FIGURE 17(c) Higher Magnification of the Image in Figure 17(b). Corrosion products can be clearly seen.
FIGURE 17(d) Presence of Zinc and Sulfur Detected in the EDAX Conducted on the Area of Corrosion Products. 


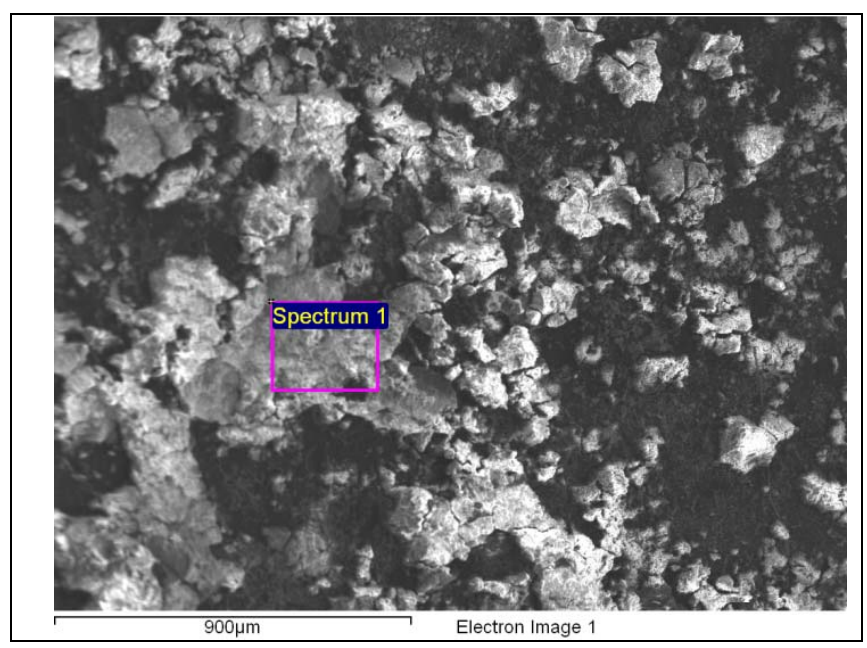

FIGURE 18(a) Corrosion Products Lifted Off on a Carbon Tape and Imaged.

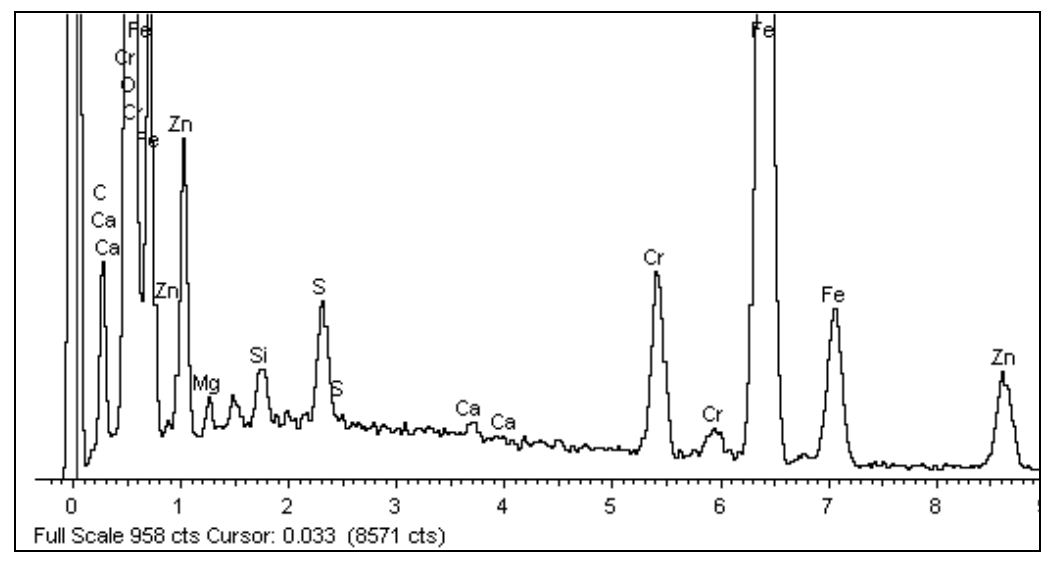

FIGURE 18(b) EDAX of the corrosion products shown in Figure 18(a). 

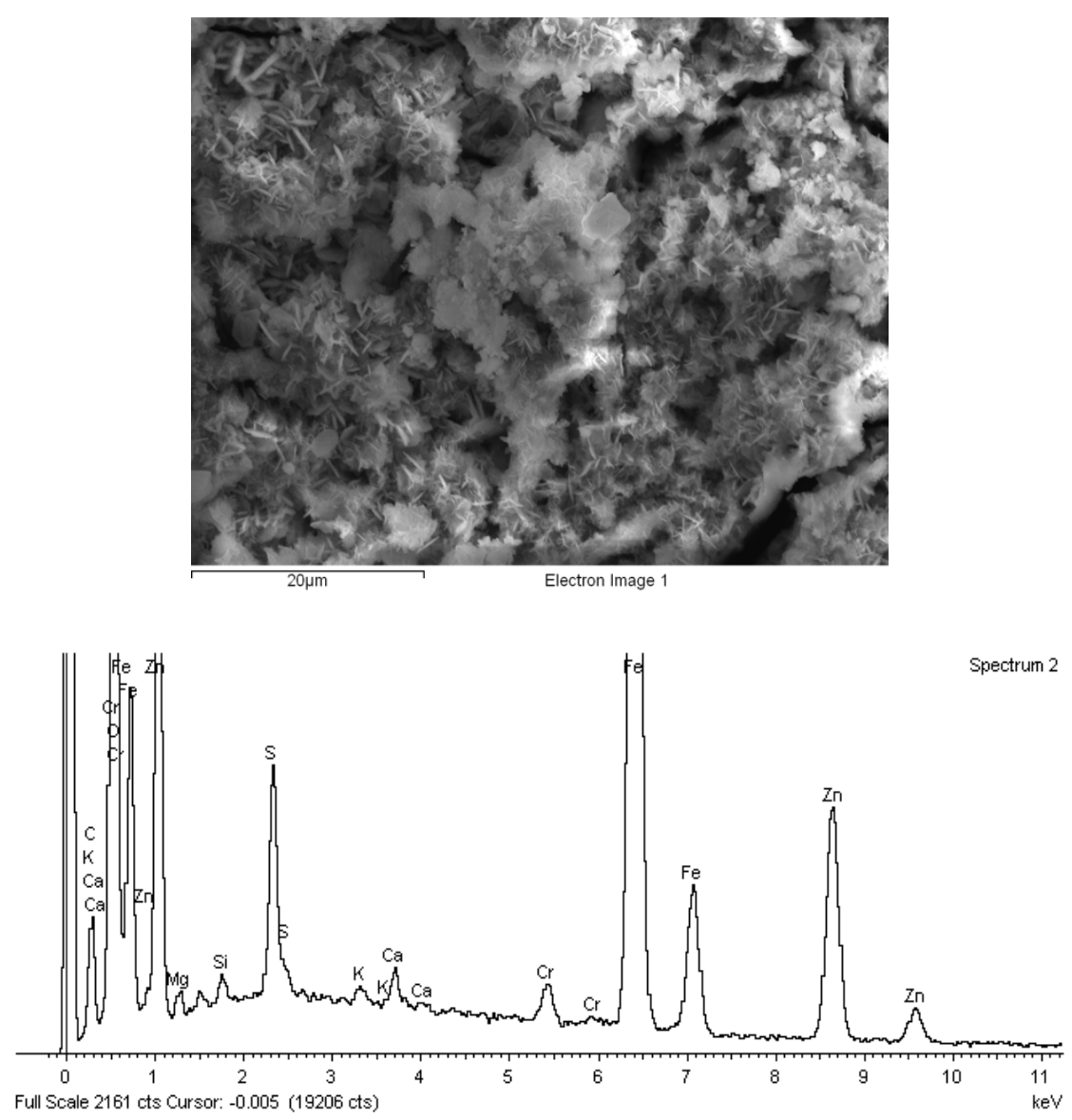

FIGURE 19 High Magnification Photograph of the Corrosion Products and the Associated EDAX Pattern.

\subsection{SUMMARY}

- SEM indicated intergranular fracture of the yoke sample.

- EDAX on the clean fracture surface showed the steel constituents.

- EDAX conducted on the corrosion products indicated the presence of zinc, sulfur, and calcium.

- Zinc migrated from the galvanized components of the beam clamp assembly to the corroded region.

- Based on the analysis provided by BJC, sulfur originated from the rainwater and the gypsum board.

- Based on the analysis provided by BJC, calcium originated from gypsum board and the concrete in the building. 


\section{CHEMICAL ANALYSIS OF STEEL AND CORROSION PRODUCTS}

To corroborate the SEM/EDAX analysis, chemical elemental analysis was conducted on the various steel and corrosion products to understand what chemical species are present and their location. It is believed that this information will provide insights into the corrosion mechanisms.

Various samples that were tested are listed in Table 5. Chemical analysis was done at ANL's Analytical Chemistry Laboratory. The experimental procedure required first dissolving the samples into a solution and then analyzing the various elements by induction coupled plasma-mass spectrometry (ICP-MS).

Results of the various elements analyzed and their concentrations are listed in Table 5. Some of the key observations from the ICP-MS analysis were the following:

- Steel compositions of failed yokes and the as-received Ni-coated yokes and D- rings do not show any sulfur, zinc, or calcium.

- Corrosion products from the failed yokes show measurable amounts of calcium, sulfur, and zinc.

- Silicon content (most likely from concrete) in the corrosion products of the failed yokes was higher than the concentration in steel.

- As expected, significant amounts of iron are present in the corrosion products. 
TABLE 5 ICP-MS Analysis (wt.\%) on Various Steel and Corrosion Product Samples

\begin{tabular}{|c|c|c|c|c|c|c|c|c|c|c|c|c|}
\hline $\begin{array}{c}\text { Sample } \\
\text { ID }\end{array}$ & $\begin{array}{c}\text { Sample } \\
\text { Description }\end{array}$ & $\mathrm{Ca}$ & $\mathrm{Cr}$ & $\mathrm{Fe}$ & $\mathrm{Mg}$ & $\mathrm{Mn}$ & $\mathrm{Ni}$ & $P$ & Si & $\mathrm{Na}$ & S & $\mathrm{Zn}$ \\
\hline NiARY2 & $\begin{array}{l}\text { Ni-coated yoke } \\
\# 2\end{array}$ & $<0.02$ & 11.6 & 74.9 & $<0.02$ & 0.38 & 2.21 & 0.15 & 0.43 & $<0.02$ & $<0.03$ & $<0.02$ \\
\hline NiARDR3 & $\begin{array}{l}\text { Ni-coated D-ring } \\
\# 3\end{array}$ & $<0.06$ & 0.95 & 85.7 & $<0.06$ & 0.72 & 0.76 & $<0.22$ & 0.33 & $<0.06$ & $<0.11$ & $<0.06$ \\
\hline $6 Y C$ & $\begin{array}{l}\# 6 \text { failed yoke } \\
\text { steel; corrosion } \\
\text { products } \\
\text { polished off }\end{array}$ & $<0.03$ & 12.3 & 76.1 & $<0.03$ & 0.39 & 0.20 & $<0.11$ & 0.52 & $<0.03$ & $<0.06$ & $<0.03$ \\
\hline $6 Y \mathrm{YC}$ & $\begin{array}{l}\# 6 \text { failed yoke } \\
\text { steel; corrosion } \\
\text { products } \\
\text { polished off }\end{array}$ & $<0.02$ & 12.5 & 76.3 & $<0.02$ & 0.39 & 0.20 & $<0.08$ & 0.44 & $<0.02$ & $<0.04$ & $<0.02$ \\
\hline $2 Y C$ & $\begin{array}{l}\# 2 \text { failed yoke } \\
\text { steel; corrosion } \\
\text { products } \\
\text { polished off }\end{array}$ & 0.04 & 12.4 & 77.1 & $<0.03$ & 0.39 & 0.20 & $<0.1$ & 0.67 & $<0.03$ & $<0.05$ & $<0.03$ \\
\hline NiARY1 & $\begin{array}{l}\text { Ni-coated yoke } \\
\# 1\end{array}$ & $<0.03$ & 12.0 & 74.9 & $<0.03$ & 0.38 & 2.32 & 0.19 & 0.45 & $<0.03$ & $<0.05$ & $<0.03$ \\
\hline $2 \mathrm{CP}$ & $\begin{array}{l}\text { Corrosion } \\
\text { products from } \\
\# 2 \text { failed yoke }\end{array}$ & 5.91 & 1.84 & 34.5 & 0.39 & $<0.3$ & $<0.3$ & $\mathrm{NR}$ & 0.84 & 0.72 & 2.16 & 1.49 \\
\hline $6 \mathrm{CP}$ & $\begin{array}{l}\text { Corrosion } \\
\text { products from } \\
\text { \#6 failed yoke }\end{array}$ & 6.76 & 1.71 & 30.8 & $<0.3$ & $<0.3$ & $<0.3$ & NR & 1.58 & $<0.3$ & 5.06 & 0.37 \\
\hline 8 DRC & $\begin{array}{l}\text { Corrosion } \\
\text { products from } \\
\text { D-ring \#8 from } \\
\text { K25 five }\end{array}$ & 0.85 & 0.22 & 49.8 & 0.06 & 0.31 & $<0.06$ & NR & 0.37 & $<0.06$ & 0.22 & 2.52 \\
\hline
\end{tabular}




\section{COATING THICKNESS}

Reliance Industries used an electroless nickel plating process to deposit nickel (with 5\% phosphorus) coating of the yoke and D-ring samples. The purpose of applying the nickel coating was to prevent corrosion of the underlying steel for both yoke and D-rings. Bechtel Jacobs's rationale is that a thicker ( $>1 \mathrm{mil}$ ) coating will allow longer service life for the yoke and D-ring components. In this regard, BJC requested ANL to evaluate the nickel coatings deposited on the yoke and D-ring to determine the coating thicknesses and coating quality.

To evaluate the Ni-5\% P coatings, two samples of as-received yokes (NiARY1 and NiARY2) were sliced, and a thin sliver retrieved. Smaller sample sections from two locations were cut out such that one section was from the middle, and the other was near the edge. One D-ring sample (NiARDR3) was sliced at two locations, and two sample pieces were retrieved. Subsequently, the retrieved samples from the yoke and D-ring were polished by standard metallographic techniques. The polished surfaces for the typical yoke and D-ring sample at low and high magnifications are shown in Figures 20 to 25. Clearly, the deposited Ni coating on the steel surface is visible. Nickel coating thickness was measured on a standard optical microscope equipped with a precision micrometer with a digital readout. Nickel coating thicknesses were measured at several locations, and an average value was determined.

Table 6 lists the average measured values of the Ni-5\% P coating thicknesses for the three sets of samples evaluated (NiARY1, NiARY2, and NiARDR3).

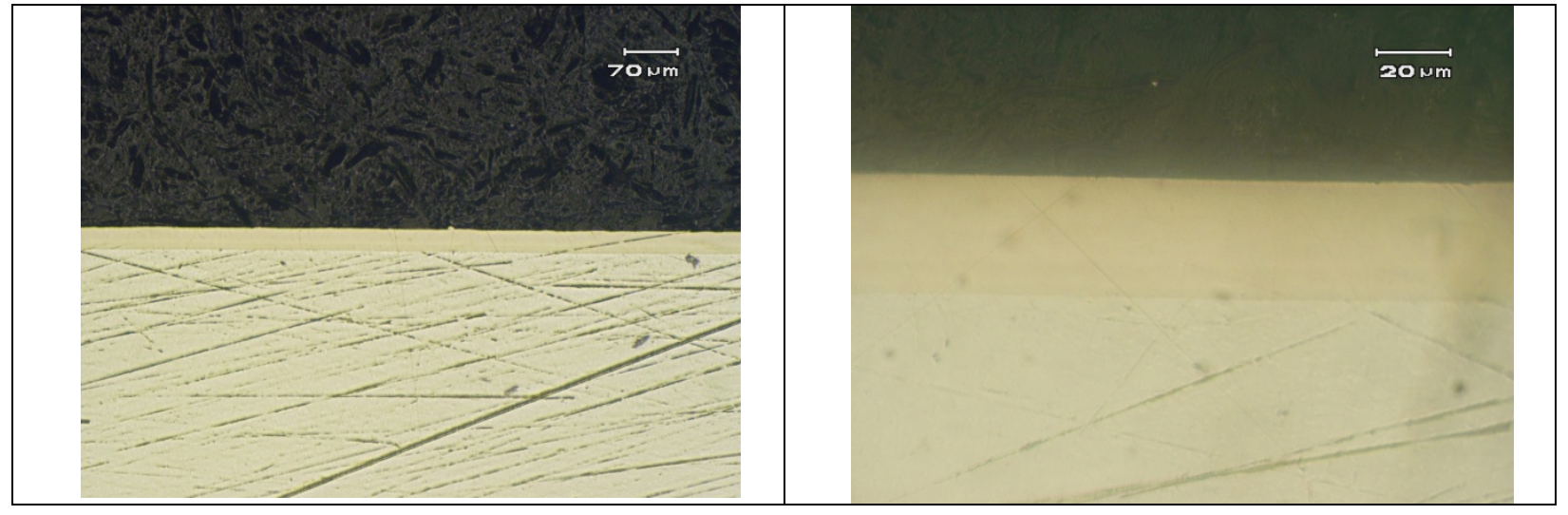

FIGURE 20 Low Magnification Image of the Ni-5\% P Coating on Yoke (NiARY1).
FIGURE 21 High Magnification Image of the Ni-5\% P Coating on Yoke (NiARY1). 


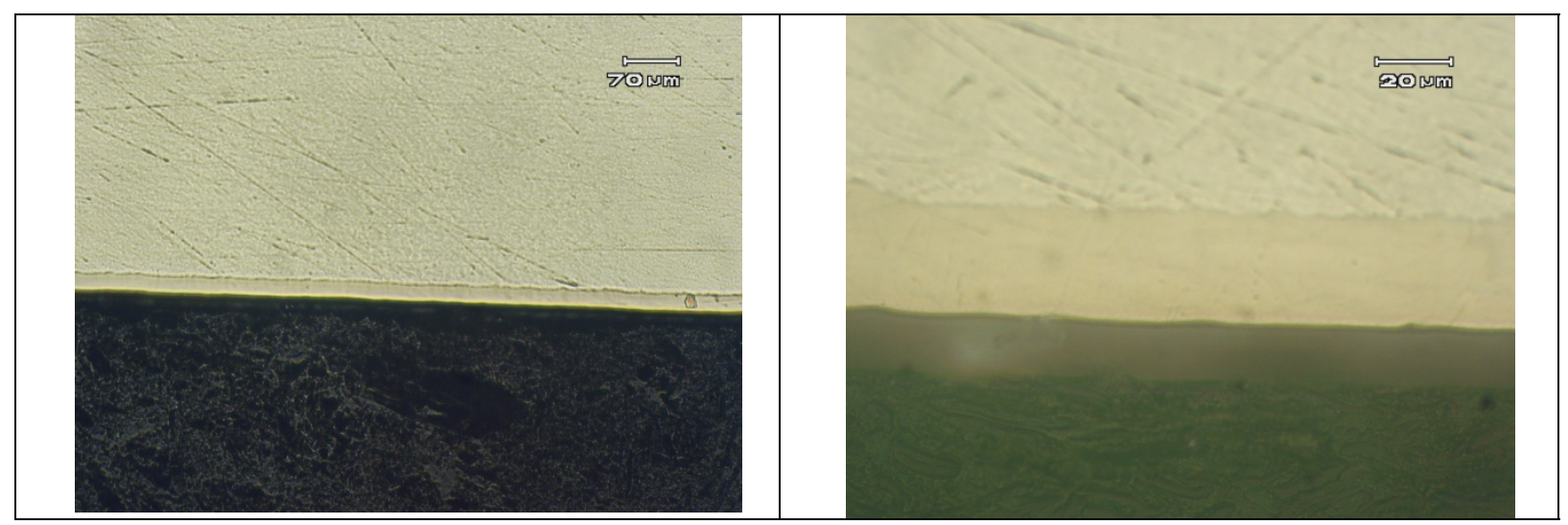

FIGURE 22 Low Magnification Image of FIGURE 23 High Magnification Image of the Ni-5\% P Coating on Yoke (NiARY2). the Ni-5\% P Coating on Yoke (NiARY2).

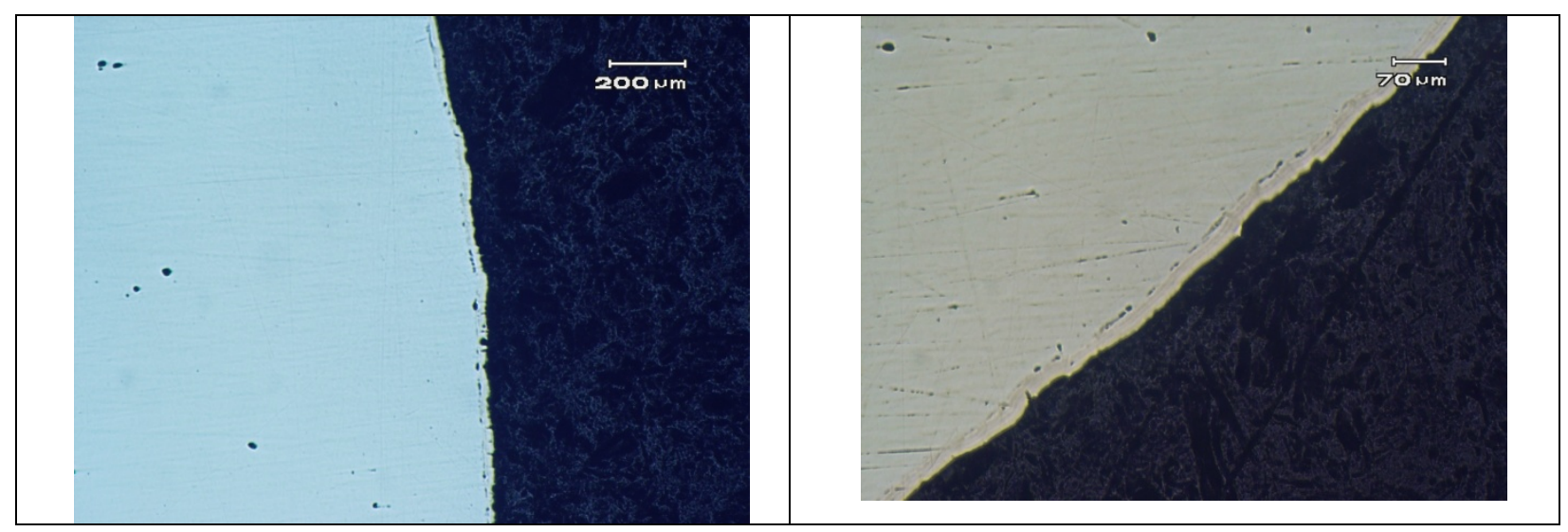

FIGURE 24 Low Magnification Image of the Ni-5\% P Coating on D-ring (NiARDR3).
FIGURE 25 High Magnification Image of the Ni-5\% P Coating on D-ring (NiARDR3).

TABLE 6 Results from Ni Coating Thickness Measurements

\begin{tabular}{llc}
\hline Sample ID & \multicolumn{1}{c}{ Sample Description } & $\begin{array}{c}\text { Average Coating Thickness } \\
(\mu \mathrm{m})\end{array}$ \\
\hline NiARY1 & Ni-5\% P as-received coated yoke sample & $24.8 \pm 5$ \\
NiARY2 & Ni-5\% P as-received coated yoke sample & $23 \pm 6$ \\
NiARDR3 & Ni-5\% P as-received coated D-ring sample & $22.5 \pm 4$ \\
\hline
\end{tabular}

Note: $1 \mathrm{mil}=25.4 \mu \mathrm{m}$ 
The following observations were made:

- Deposited Ni-5\% P coatings for the as-received yokes were $24.8 \mu \mathrm{m}$ (0.98 mils) and $23 \mu \mathrm{m}$ (0.91 mils).

- For the D-ring, coating thickness was $22.5 \mu \mathrm{m}$ (0.89 mils).

- Coatings on the yoke samples were uniform and appeared to be well bonded to steel. However, coatings on the D-ring appeared to be delaminated and inhomogeneous in thickness at various locations. 


\section{RELIANCE INSPECTION PLAN}

There are two major comments regarding the Reliance Industries inspection plan:

- The inspection plan implicitly assumes that because of the nickel coating, corrosion of the yoke and/or D-ring will be delayed. However, this hypothesis is based on the assumption that the nickel plating is uniform and well bonded to the steel substrates of the yoke and D-ring. As per the results of the coating thickness measurements, the coating thicknesses were less than 1 mil, and for the case of the D-ring it was not uniform and had a significant amount of porosity. Thus, a quality assurance program has to be in place to ensure that the nickel coating applied is uniform and adherent.

- In the inspection plan, there is no provision for application of any corrosion inhibitors on the beam clamp components. The possible corrosion inhibitors that could be applicable on the beam clamp components should be investigated periodically or during the inspection. 


\section{POSSIBLE CORROSION MECHANISM(S)}

The ICP-MS and SEM/EDAX analyses on the yoke corrosion products provide indications of the possible corrosion mechanism. A galvanic couple appears to have formed between the zinc-coated components (anode) and the bare steel surface of the yoke (cathode). Since zinc is more anodic compared to iron [3], it forms zinc ions $\left(\mathrm{Zn}^{2+}\right)$ and is transported to the cathode or the yoke. Bechtel Jacobs has determined that the rainwater inside of the K25 building is basic $(\mathrm{pH} \sim 8)$ and does contain a large amount of sulfate ions [2]. Sulfate ions are presumably coming from the rainwater and the rainwater contacting the gypsum wall board material. The presence of ions in the rainwater provides an electrolytic medium for the galvanic cell. Further, on the yoke side, the iron reacts to form iron hydroxide that can oxidize in air to form iron oxide, which gives the red rust color seen on the failed yoke. Galvanic corrosion can be inhibited by coating the yoke with a metal that is more anodic than zinc, such as aluminum.

Upon reviewing several reports and email correspondences provided by Bechtel Jacobs, we concluded that the yokes failed because of hydrogen embrittlement. Because the hydrogen diffuses into the martensitic type stainless steel, it renders the yokes brittle and, hence, the catastrophic failure. However, the hydrogen analysis conducted on the failed yoke samples indicated the hydrogen content to be at the same levels as those of the as-received steel. If hydrogen embrittlement is the failure cause, then one should have observed elevated levels of hydrogen concentrations in the steel. However, as suggested by Mr. T. Knaub of BJC [4], because of the elapsed time between failure of the yoke and analysis of the samples (3-4 months), elemental hydrogen would have diffused out of the yoke. Therefore, the only remaining hydrogen would be tied up in the corrosion products as iron hydroxide. Further, for hydrogen embrittlement, an acidic corrosion mechanism would be in play.

Finally, as shown in Figures 1 and 3, the fractured yoke \#2 sliver on the left shows corrosion products on the fracture surface. It is not certain when these corrosion products appeared on the failed yoke. Bechtel Jacobs indicated that the corrosion products on the fractured surface may have resulted because the fractured yoke pieces were lying in the rainwater for up to 30 days. Corrosion products on the fractured surface could also indicate a stress corrosion type of cracking. Under application of concentrated stress and corrosion, a flaw or inhomogeneity in the steel surface/subsurface can lead to accelerated corrosion. Such a mechanism could also result in catastrophic failure. 


\section{ANALYSIS OF SAMPLE WA14}

Bechtel Jacobs discovered a beam clamp assembly recently (10/28/09) that showed a white residue on the surface of the yoke and other beam clamp components. It appeared that the white residue is a precursor to the corrosion processes; hence, we decided to analyze the white residue to gain insight into the possible corrosion mechanism. Specifically, SEM was conducted on the yoke sample with residue to determine the major elemental composition. The residue was scraped off to conduct an accurate chemical analysis by ICP-MS. This particular sample had a Ni coating with 5\% P and had been in the K-25 building for only 37 days. In addition to determining the chemical nature of the residue, other tests such as hardness and coating thickness measurements were also carried out in a similar manner as described earlier.

\subsection{SEM ANALYSIS ON WA14}

Figures 26(a) and 27(a) show low and high magnification photos of the white residue deposited on the yoke. The corresponding EDAX analyses (Figures 26(b) and 27(b)) showed that the prominent peaks are from zinc. In addition, there are smaller peaks of calcium, iron, sulfur, and nickel detected.

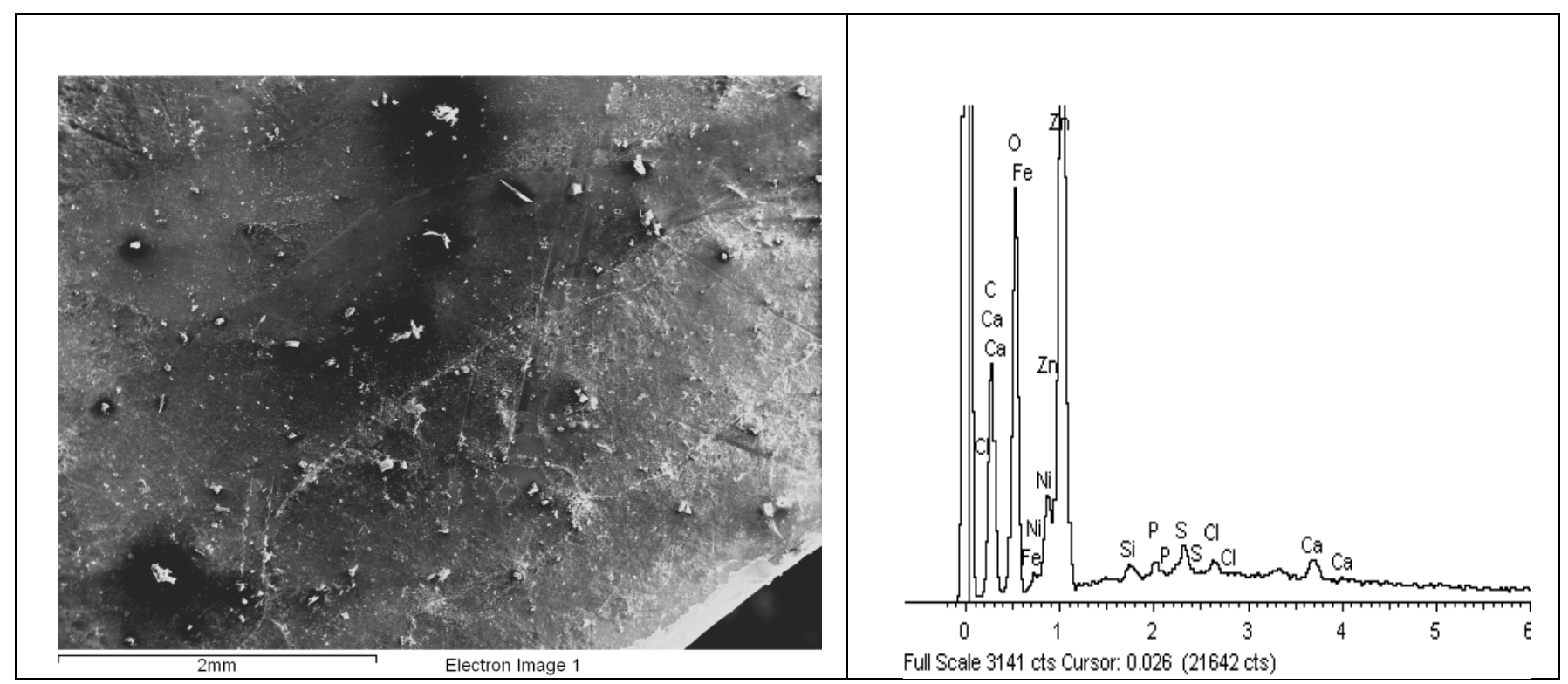

FIGURE 26(a) Low Magnification Micrograph of the White Residue on the WA14 Yoke Sample.
FIGURE 26(b) EDAX Analysis of the Area in Figure 26(a). 


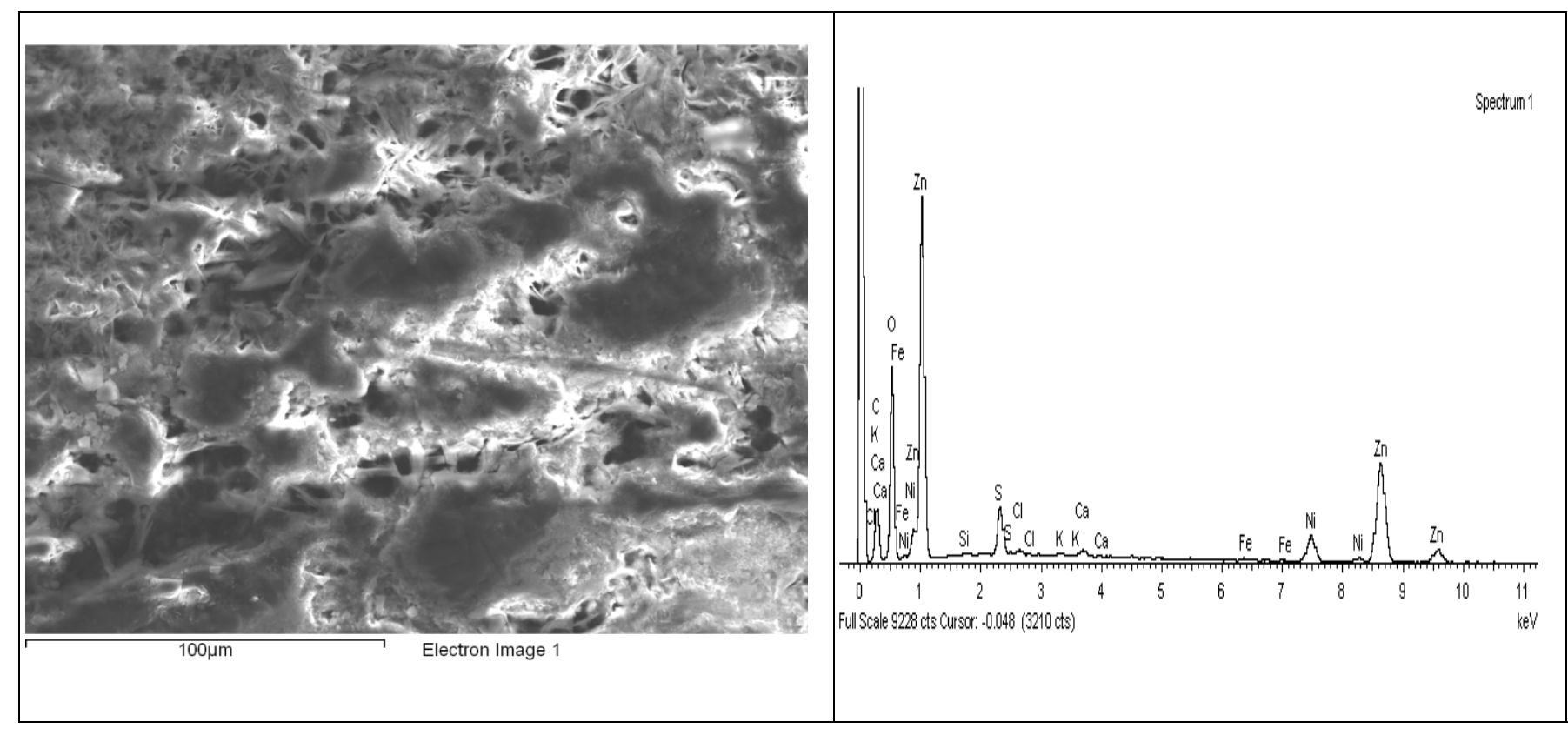

FIGURE 27(a) High Magnification Micrograph of the White Residue on the WA14 Yoke Sample.

FIGURE 27(b) EDAX Analysis of the Area in Figure 27(a).

\subsection{ICP-MS ANALYSIS ON WA14 RESIDUE}

Table 7 lists the concentration of various metals present in the white residue scraped off from WA14 sample. Clearly, the analysis confirms the SEM observations, indicating Zn as the major component with iron, nickel, sulfur, and calcium as the minor components. These observations are consistent with the proposed galvanic corrosion mechanism discussed earlier in Section 10. Nickel and iron come from the base yoke metal, whereas $\mathrm{Zn}$ comes from the $\mathrm{Zn}$ plating present in other components of the beam clamp. In the presence of moisture, a galvanic couple is formed that transports $\mathrm{Zn}$ to the yoke surface. The presence of calcium and sulfur (from gypsum board and the environment) are dissolved in the rainwater, which becomes an electrolyte.

\subsection{HARDNESS MEASUREMENTS ON WA14}

As described before, Rockwell C harness measurements were made on the WA14 D-ring and yoke samples, and the data are presented in Figures 28 and 29, respectively. The D-ring hardness $\left(\mathrm{R}_{\mathrm{C}} \sim 40\right)$ was consistent with the measurements on the Ni-5\% P coated samples, as discussed in Section 4 . The yoke values were in agreement with the annealed yoke samples with the Ni-5\% P coating. 
TABLE 7 Metal Concentration (wt.\%) in White Residue of Sample W14

\begin{tabular}{cccccccccccc} 
Sample & $\mathrm{Ca}$ & $\mathrm{Cr}$ & $\mathrm{Fe}$ & $\mathrm{Mg}$ & $\mathrm{Mn}$ & $\mathrm{Ni}$ & $\mathrm{P}$ & $\mathrm{Si}$ & $\mathrm{Na}$ & $\mathrm{S}$ & $\mathrm{Zn}$ \\
\hline WA14 & 7.9 & 0.43 & 3.63 & 0.27 & $<0.16$ & 1.95 & $<0.31$ & 2.50 & 0.27 & 2.52 & 18.8 \\
\hline
\end{tabular}

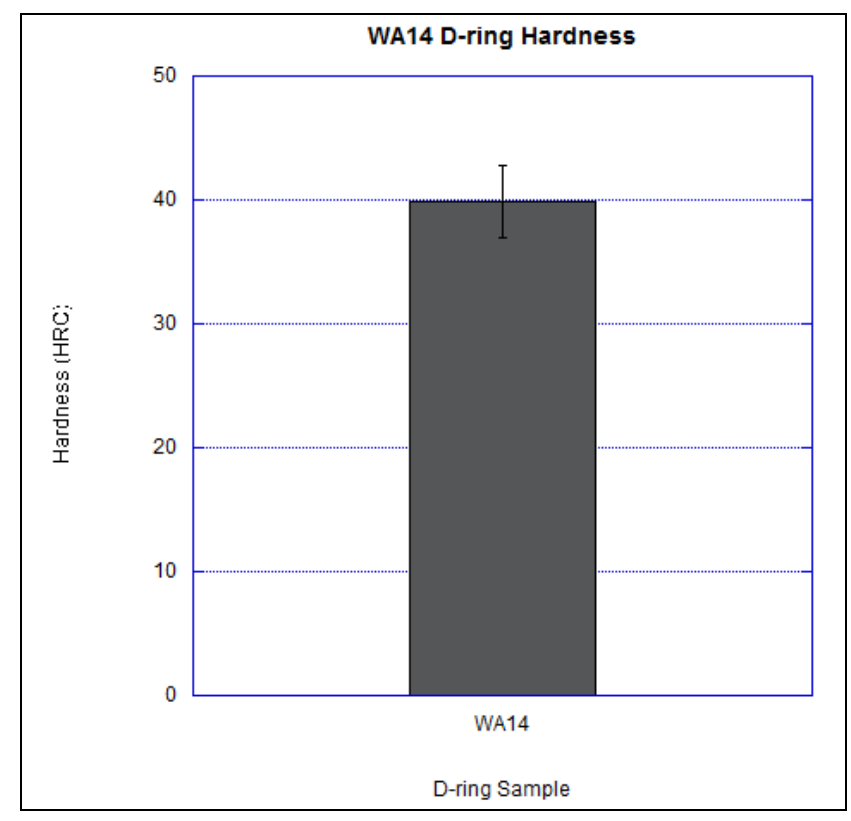

FIGURE 28 Hardness Measurements on WA14

D-ring.

\subsection{COATING THICKNESS MEASUREMENTS}

Similar to the as-received Ni-5\% P coated samples, coating thicknesses for the D-ring and yoke from WA14 sample were measured. Figures 30 and 31 show typical micrographs of the coatings on D-ring and yoke, respectively. The average coating thickness for the D-ring was $19 \pm 3 \mu \mathrm{m}(0.75 \pm 0.1 \mathrm{mils})$. Similarly, for the yoke, average coating thickness was $26 \pm 2 \mu \mathrm{m}$ (1.02 \pm 0.1 mils).

An interesting observation was made for the coating on the yoke sample. As shown in Figure 30, it appears that the coating was applied in multiple stages, as indicated by the two distinct layers of the coating. 


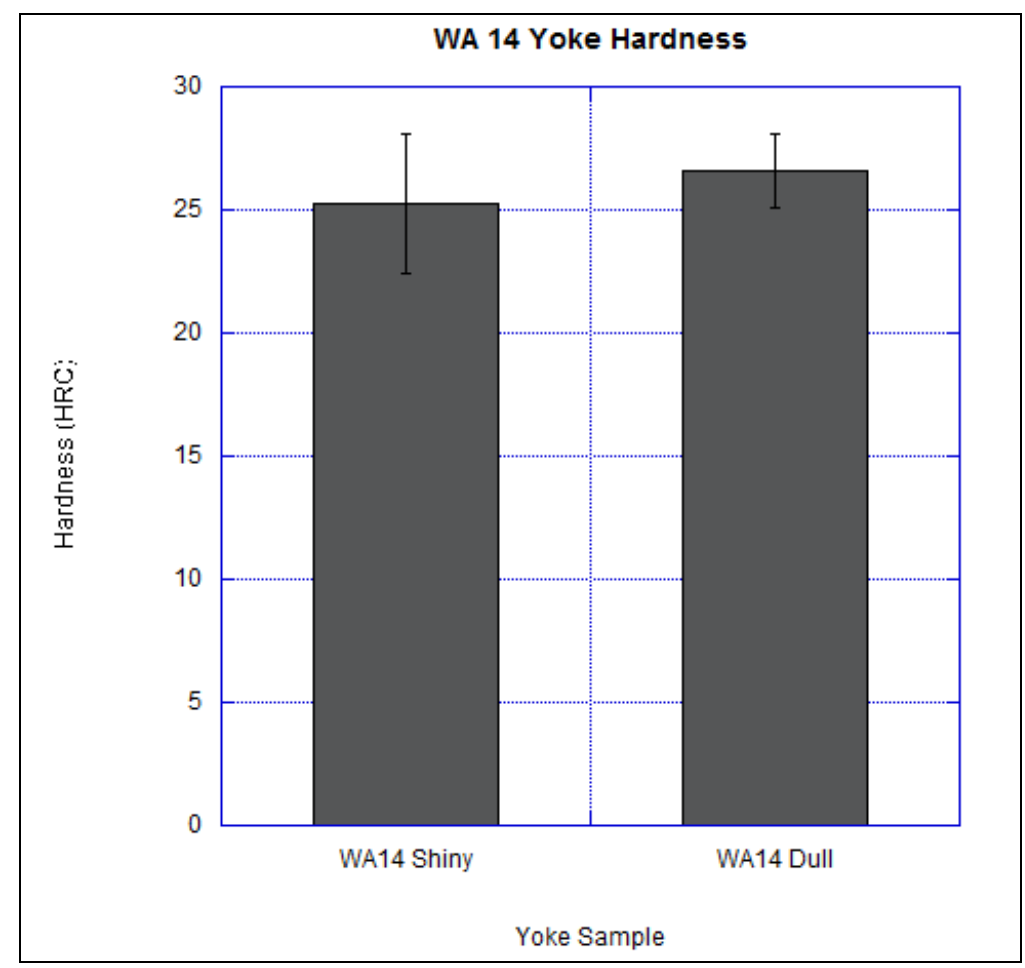

FIGURE 29 Hardness Values of the WA14 Yoke on the Shiny and Dull Surfaces.

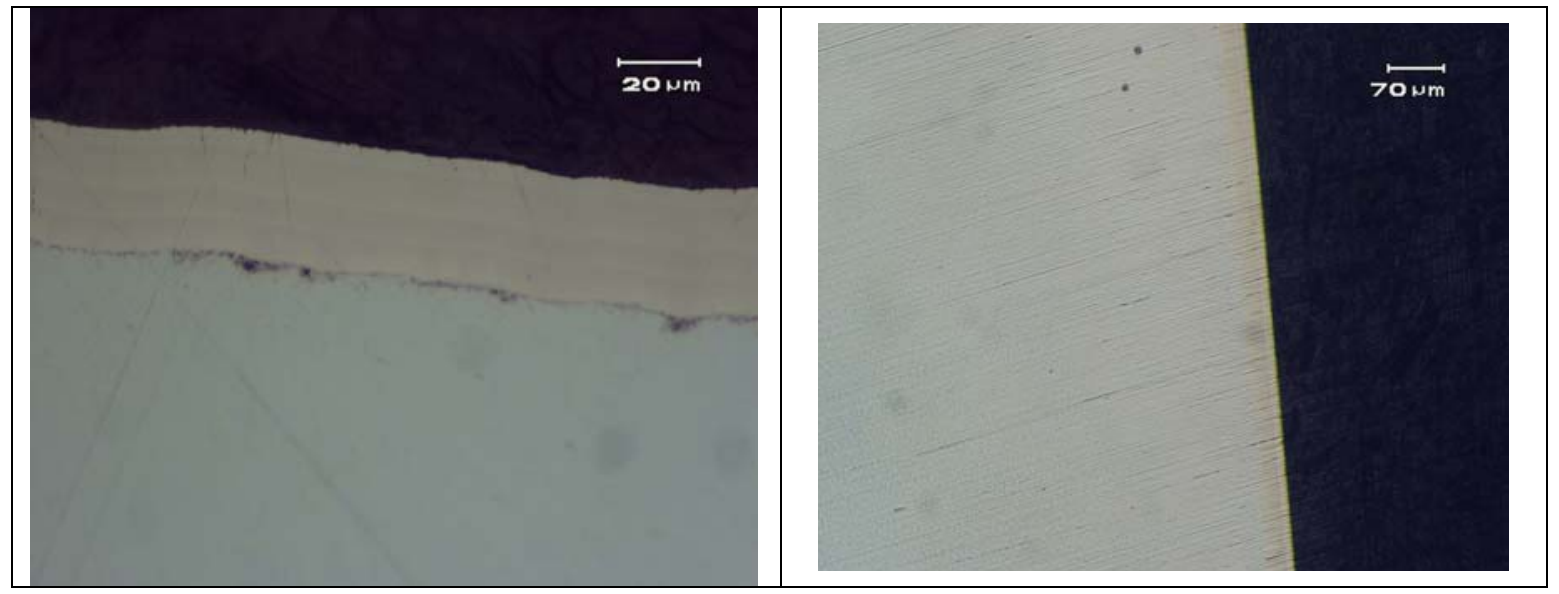

FIGURE 30 Coating of D-ring of Sample WA14.
FIGURE 31 Coating on Yoke of Sample WA14. 


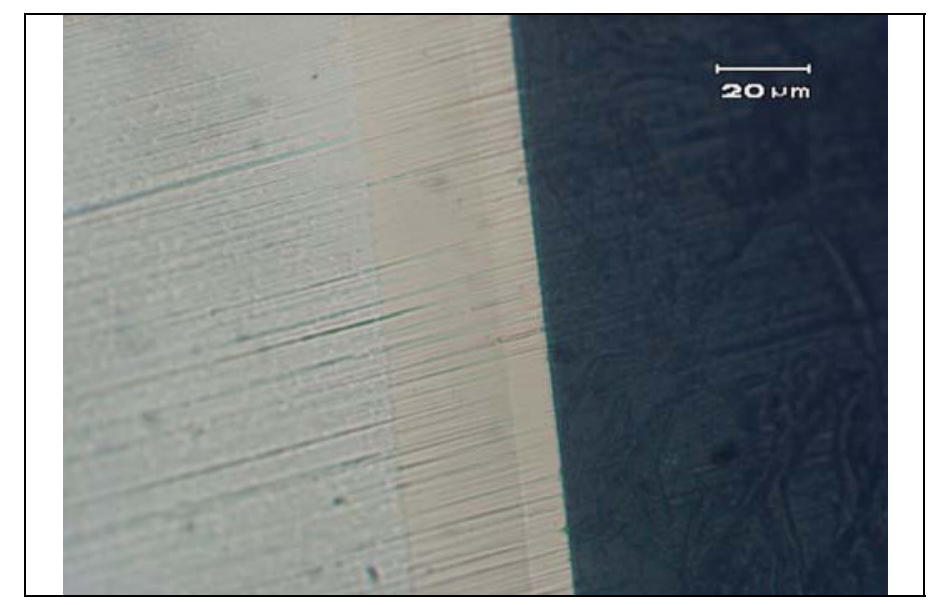

FIGURE 32 Higher Magnification of Coating on WA14 Yoke. Notice the double layer in the coating.

\subsection{SUMMARY}

- Analysis of the white residue showed it was predominantly zinc with smaller concentrations of calcium, sulfur, iron, and nickel.

- Analysis of the white residue confirms the transport of zinc from the galvanized parts of the beam clamps to the yoke by a galvanic mechanism.

- The hardness of D-ring and yokes was similar to that of the Ni-5\% P coated as-received samples tested and reported in Section 4.0.

- Average coating thicknesses for the yoke and D-rings were $19 \mu \mathrm{m}$ and $26 \mu \mathrm{m}$, respectively. However, for the yokes, coating appeared to be applied in two stages. 


\section{ANALYSIS OF SAMPLES 10P1 AND 10P2}

Bechtel Jacobs sent ANL two sets of D-rings and yokes that were coated with a Ni-10\% $\mathrm{P}$ coating. The rationale for the higher concentration of phosphorus was it might inhibit corrosion. The two sets of samples received were labeled as 10P1 and 10P2.

\subsection{COATING THICKNESS MEASUREMENTS}

Coating thickness measurements for samples 10P1 and 10P2 are listed in Table 8. The procedure for coating thickness measurements was similar to that described earlier. As indicated in the table the coating thicknesses were quite similar for both the D-rings and yoke specimens for both samples. These values are somewhat smaller than the measured coating thicknesses for the as-received Ni-5\% P samples.

\subsection{HARDNESS MEASUREMENTS}

The Rockwell C hardness values for both D-ring and yoke samples with $\mathrm{Ni}-10 \% \mathrm{P}$ coating are shown in Figures 33 and 34. The average hardness for the D-rings was $R_{C} \sim 37$, which is slightly lower than that for the Ni-5\% P coated samples. For the yoke samples, the hardness values are significantly higher than those of the Ni-5\% P samples, indicating that the yoke was not annealed. Further, there is a larger difference in the hardness values between the dull and shiny side of the yokes for both samples; the shiny side gives a higher hardness.

\subsection{HYDROGEN ANALYSIS}

Results on the hydrogen content measured on samples 10P1 and 10P2 are shown in Table 9. These results are consistent with the low hydrogen content observed in the as-received D-rings and yoke samples earlier. Typical values for hydrogen concentrations were 3-5 ppm.

TABLE 8 Results for Coating Thickness Measurements for Samples 10P1 and 10P2

\begin{tabular}{lcc}
\hline Sample & $\begin{array}{c}\text { D-ring coating thickness } \\
(\mu \mathrm{m})\end{array}$ & $\begin{array}{c}\text { Yoke coating thickness } \\
(\mu \mathrm{m})\end{array}$ \\
\hline & & \\
$10 \mathrm{P} 1$ & $17 \pm 4$ & $19 \pm 4$ \\
$10 \mathrm{P} 2$ & $18 \pm 4$ & $19 \pm 4$ \\
\hline
\end{tabular}

Note: $1 \mathrm{mil}=25.4 \mu \mathrm{m}$ 


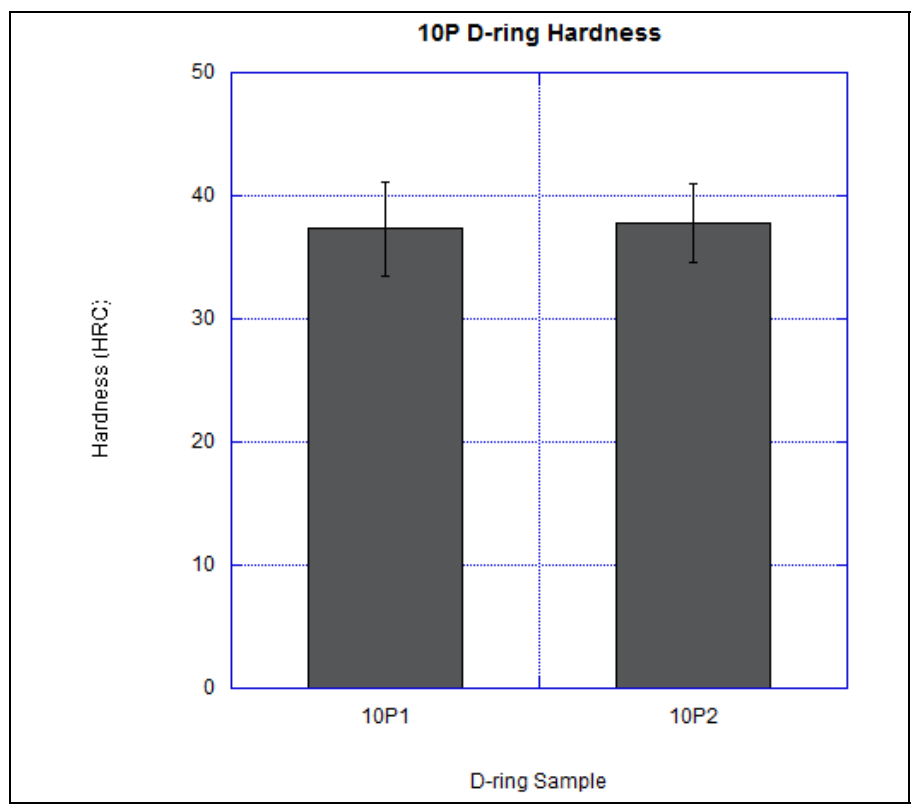

FIGURE 33 Hardness Values for 10P1 and 10P2 DRing Samples.

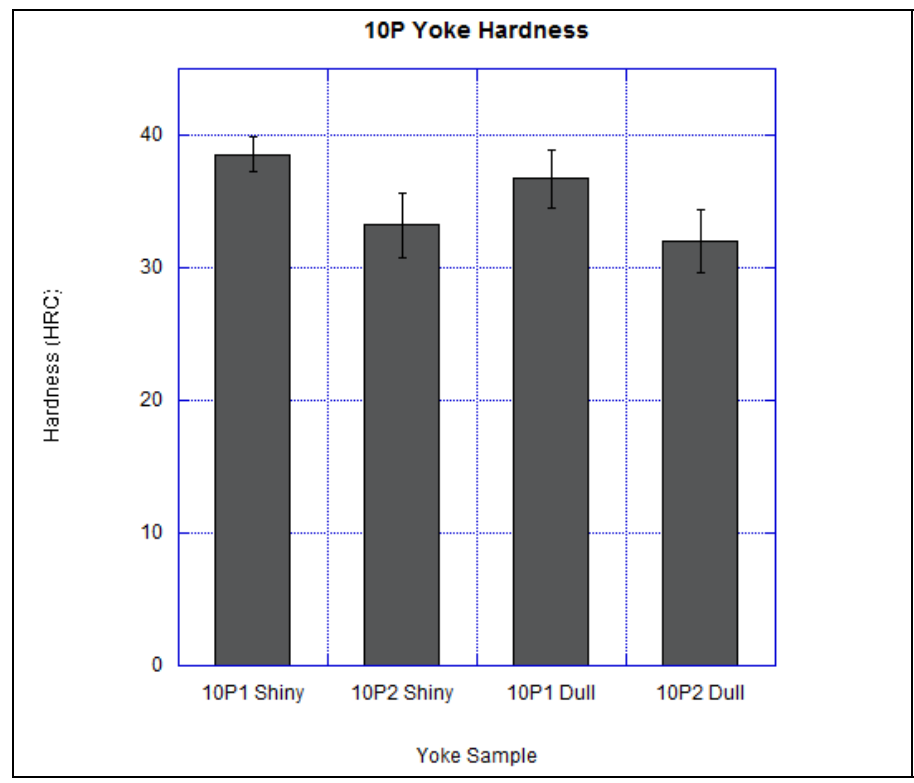

FIGURE 34 Hardness Values for 10P1 and 10P2 Yoke Samples. 
TABLE 9 Hydrogen Analysis Results for Samples 10P1 and 10P2

\begin{tabular}{lccc}
\hline Sample ID & Sample Description & $\begin{array}{c}\mathrm{H}_{2} \text { Content } \\
(\mathrm{ppm})\end{array}$ & $\begin{array}{c}\text { Sample Obtained } \\
\text { From }\end{array}$ \\
\hline 10P1Y & $\begin{array}{c}\text { As-received Ni-coated } \\
(10 \% \text { P) yoke }\end{array}$ & 5.41 & Yoke \# 1 \\
$10 \mathrm{P} 2 \mathrm{Y}$ & $\begin{array}{c}\text { As-received Ni-coated } \\
(10 \% \text { P) yoke }\end{array}$ & 4.01 & Yoke \# 2 \\
$10 \mathrm{P} 1 \mathrm{R}$ & $\begin{array}{c}\text { As-received Ni-coated } \\
(10 \% \mathrm{P}) \text { D-ring } \\
\text { 10P2R }\end{array}$ & 5.42 & D ring \# 1 \\
& $\begin{array}{c}\text { As-received Ni-coated } \\
(10 \% \mathrm{P}) \text { D-ring }\end{array}$ & 3.78 & D ring \# 2 \\
\hline
\end{tabular}

\subsection{SUMMARY}

- The measured coating thickness for both 10P1 and 10P2 D-rings was $18 \mu \mathrm{m}$.

- The measured coating thickness for both 10P1 and 10P2 yokes was $19 \mu \mathrm{m}$.

- The hardness of the 10P1 and 10P2 D-rings was $\mathrm{R}_{\mathrm{C}} \sim 37$.

- The hardness of the $10 \mathrm{P} 1$ and $10 \mathrm{P} 2$ yokes was $\mathrm{R}_{\mathrm{C}} \sim 33-38$. Hardness values were lower on the dull side of the yoke.

- $\quad$ The hydrogen content in both D-ring and yoke samples was 3-5 ppm. 


\section{EVALUATION OF ALUMINUM-COATED YOKE AND D-RINGS}

To mitigate the galvanic corrosion of the yoke and D-rings, BJC decided to coat the components with aluminum, a more anodic metal than zinc. Aluminum was applied on top of the nickel (10\% P) coating. Aluminum coating was applied by a commercial vendor, and four sets of yoke/D-ring samples were sent to ANL for evaluation. The sample designations were 4913, 4914, 4915, and 4916.

\subsection{HARDNESS EVALUATIONS OF ALUMINUM-COATED YOKE AND D-RINGS}

Figure 35 shows the hardness values measured on the four sets of aluminum-coated yoke samples. Hardness values were measured both on the dull and shiny sides at several locations. In

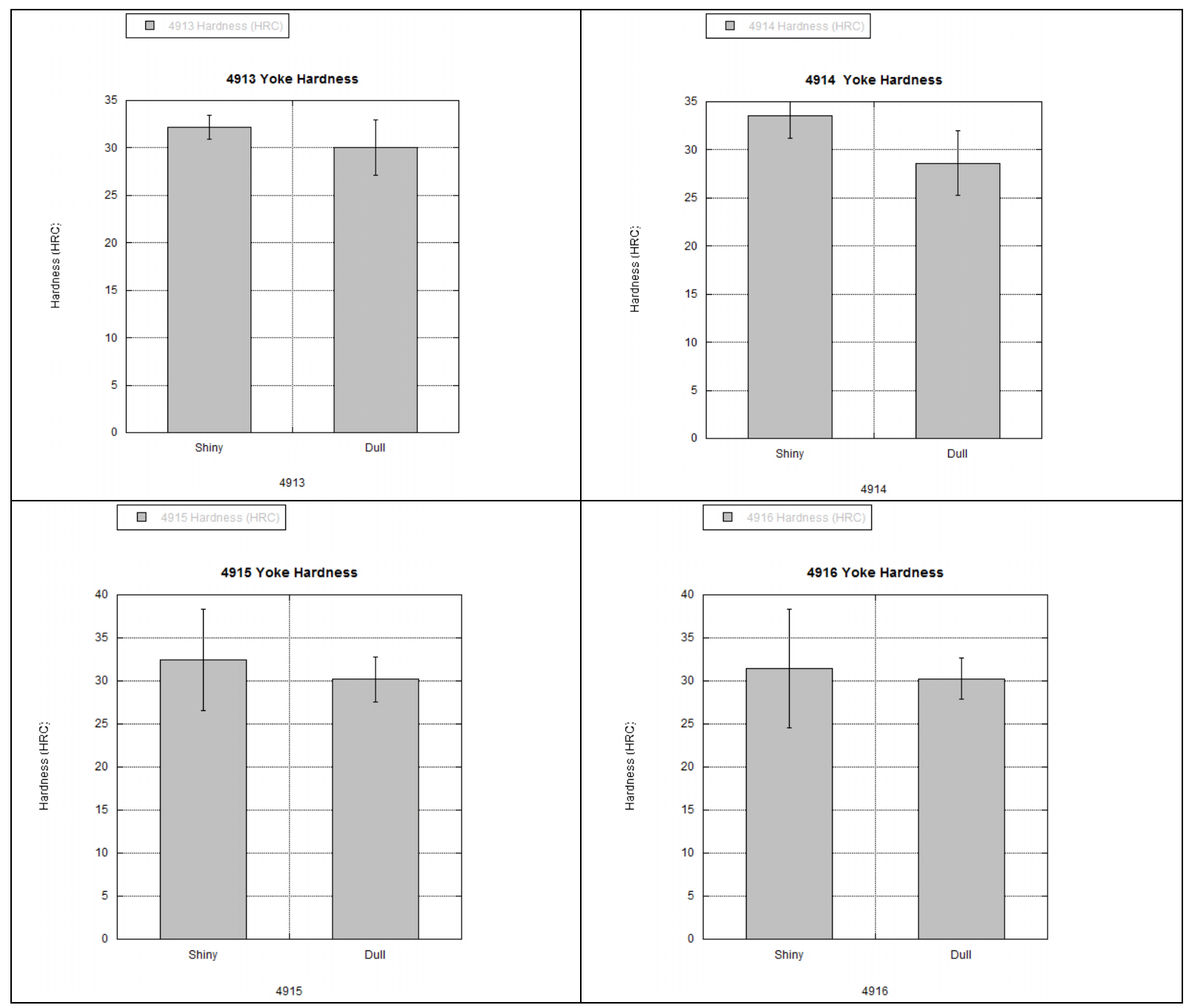

FIGURE 35 Hardness Values for Aluminum-Coated Yoke Samples. 
all samples, hardness values were between $\mathrm{R}_{\mathrm{C}} \sim 25$ and 35. Further, average hardness values for the shiny side were slightly higher than those of the dull side in all cases.

Figure 36 shows the hardness values measured on one D-ring sample, 4915. Here again, the average hardness value was $\mathrm{R}_{\mathrm{C}}=32$.

\subsection{COATING THICKNESS EVALUATIONS FOR ALUMINUM-COATED YOKES AND D-RING}

As described before, coating thickness was measured by examining the polished cross section of the samples in an optical microscope. Figure 37 shows the typical cross sections of the four yoke samples. Clearly, the Ni (middle layer) is thicker than the outer aluminum layer. Similarly, Figure 38 shows the polished cross section of D-rings (samples 4916 and 4915). The relative coating thicknesses of nickel and aluminum are quite similar to those observed for the yoke samples.

The average measured values of the nickel and aluminum coatings for the yoke and D-ring samples are graphically represented in Figures 39 and 40. For the yoke samples (Figure 39), the nickel-coating thickness was approximately $80 \mu \mathrm{m}$ (3 mils), whereas the aluminum-coating thickness was about $22 \mu \mathrm{m}$ (0.9 mils). Similar values were estimated on the D-ring samples, as shown in Figure 40. The variation in aluminum-coating thicknesses, particularly for the yoke samples, was quite large $( \pm 10 \mu \mathrm{m})$.

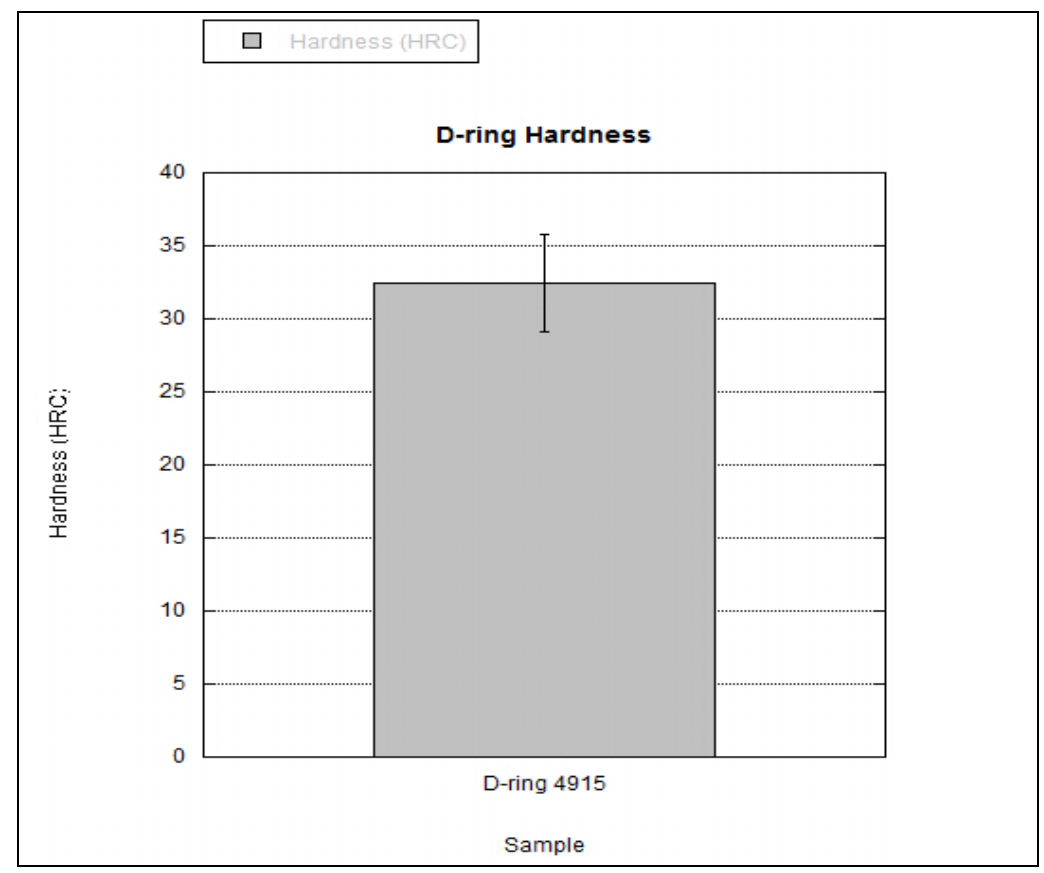

FIGURE 36 Hardness value for D-ring 4915. 


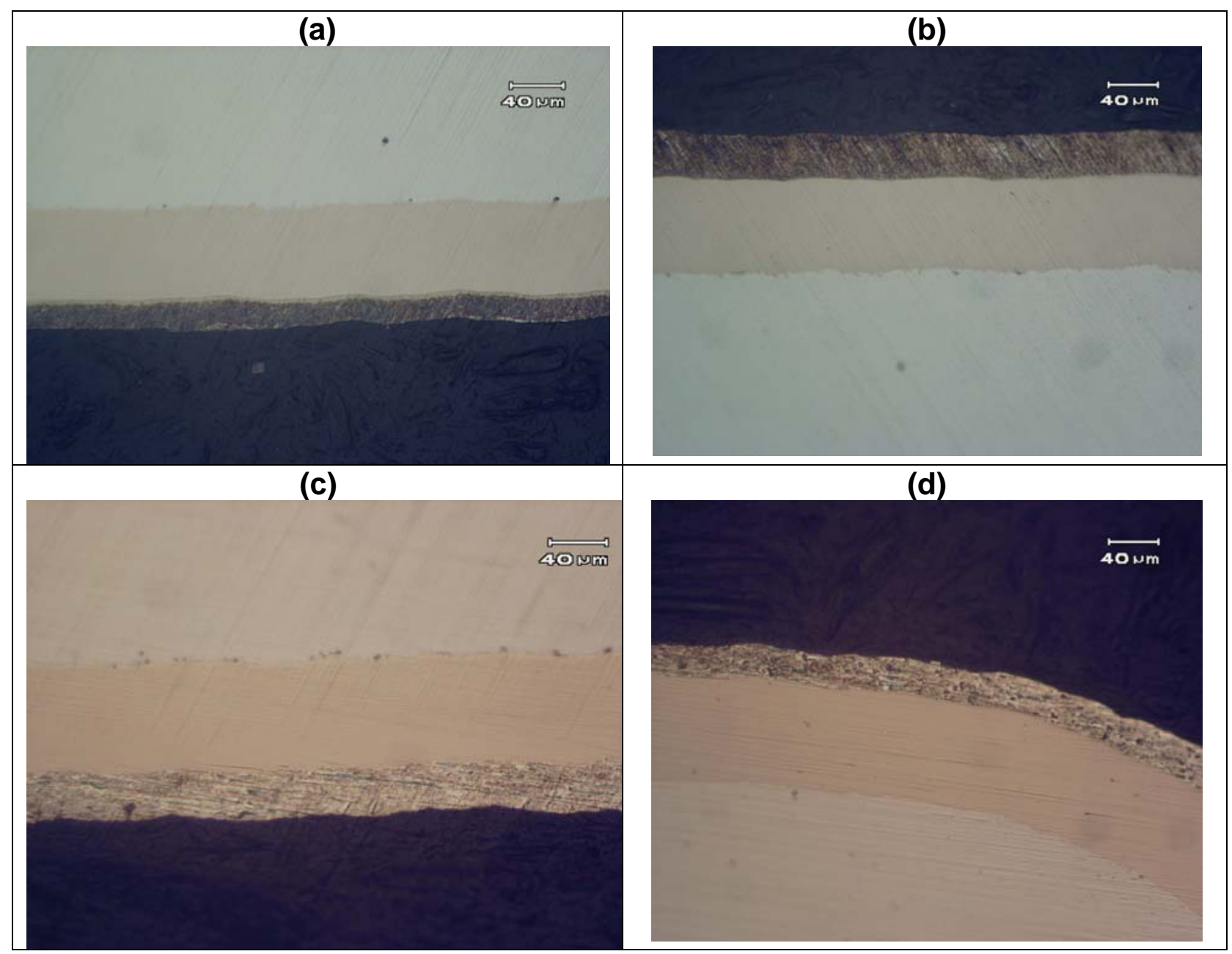

FIGURE 37 Cross Sections of Aluminum-Coated Yoke Samples: (a) 4913, (b) 4914, (c) 4915, and (d) 4916. Notice the thicker nickel layer and thinner aluminum coating.

\subsection{DURABILITY OF ALUMINUM COATING ON YOKES AND D-RINGS}

Polished cross sections were scanned to qualitatively determine the durability of the coating as a result of the slicing and subsequent polishing actions. For the most part, the coatings were intact in both the yoke and D-rings. However, in a few ( $<25 \%$ of the scanned) areas, part of the aluminum coating was missing, nickel coating had debonded, or both coatings disappeared, as shown in Figure 41. This effect is probably a result of the sample preparation, which involved cutting of the samples by using a band saw and polishing the cut surfaces. 


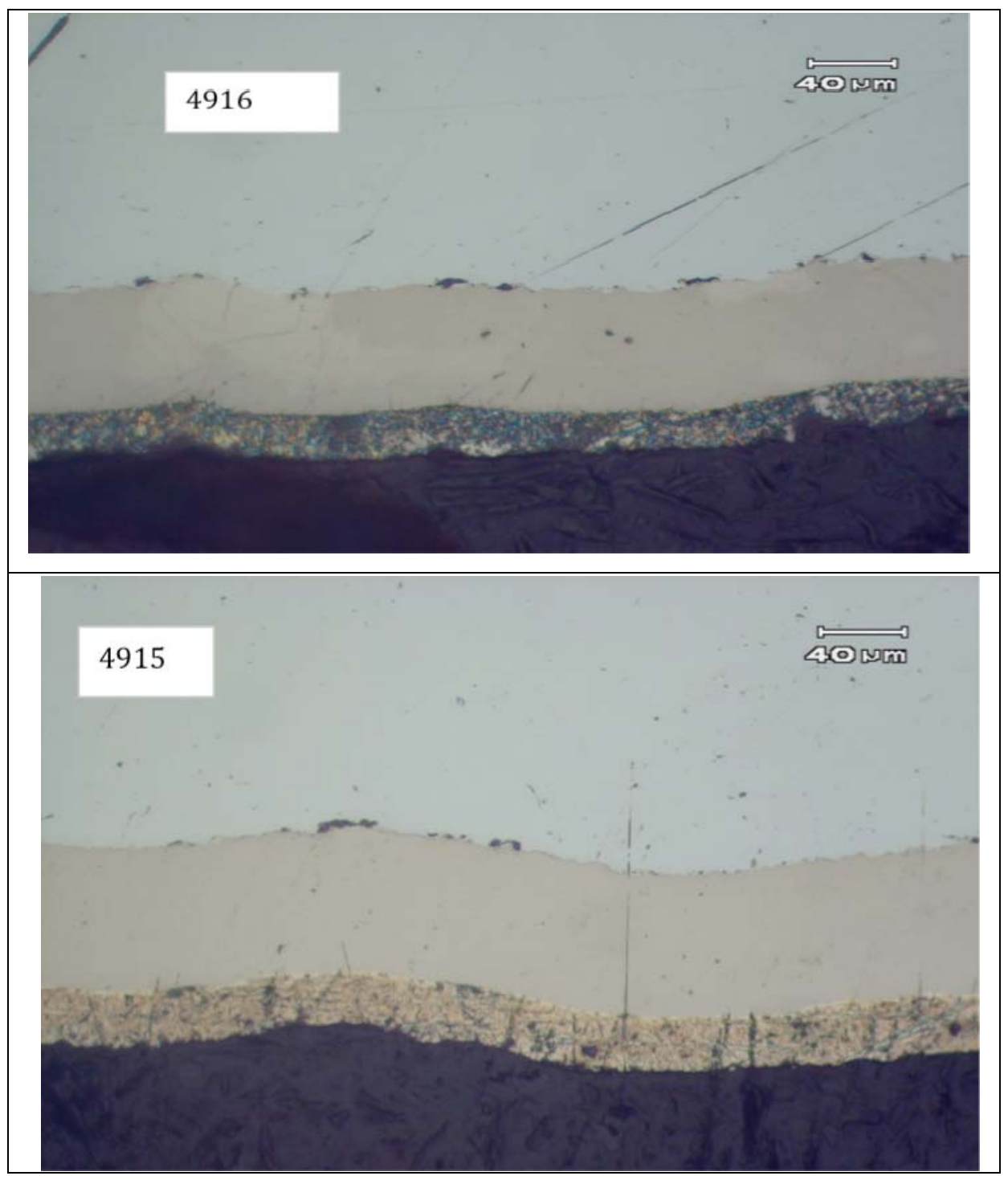

FIGURE 38 Cross Section of Aluminum-Coated D-ring Samples. 


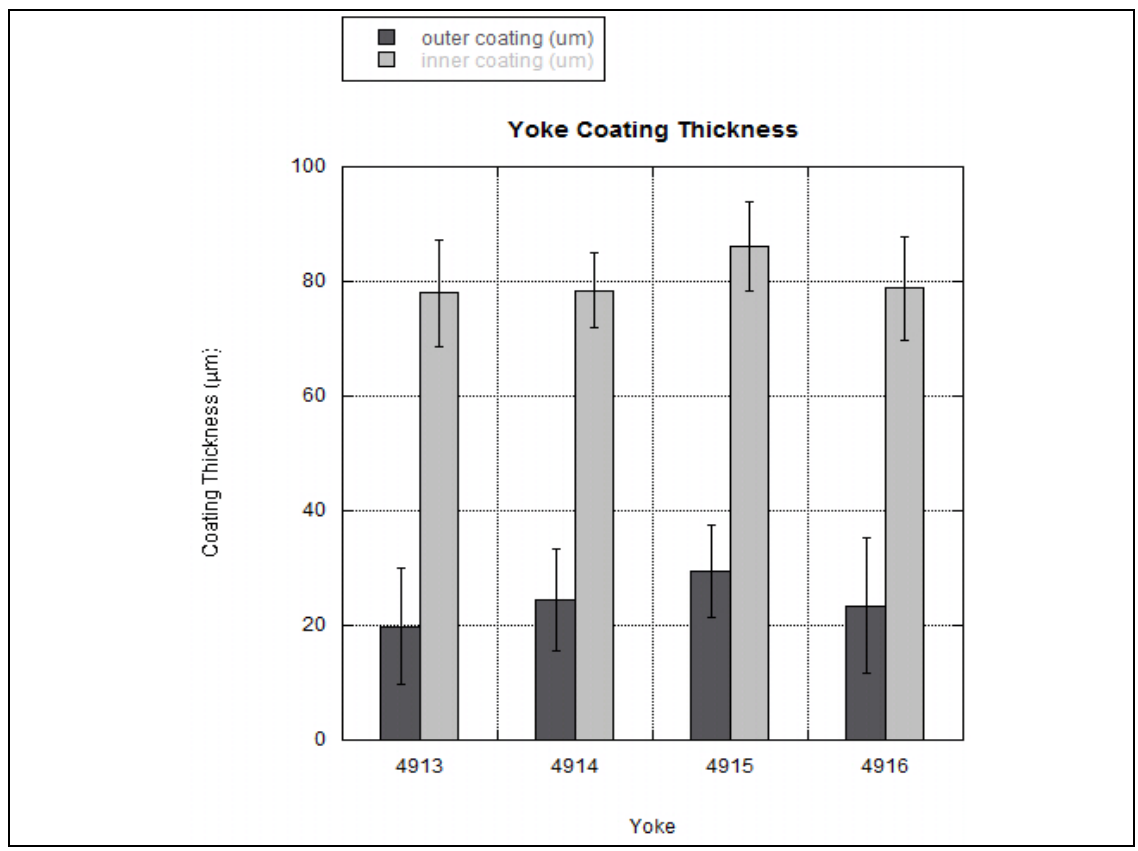

FIGURE 39 Aluminum (outer) and Nickel (inner) Coating Thicknesses for the Four Yoke Samples.

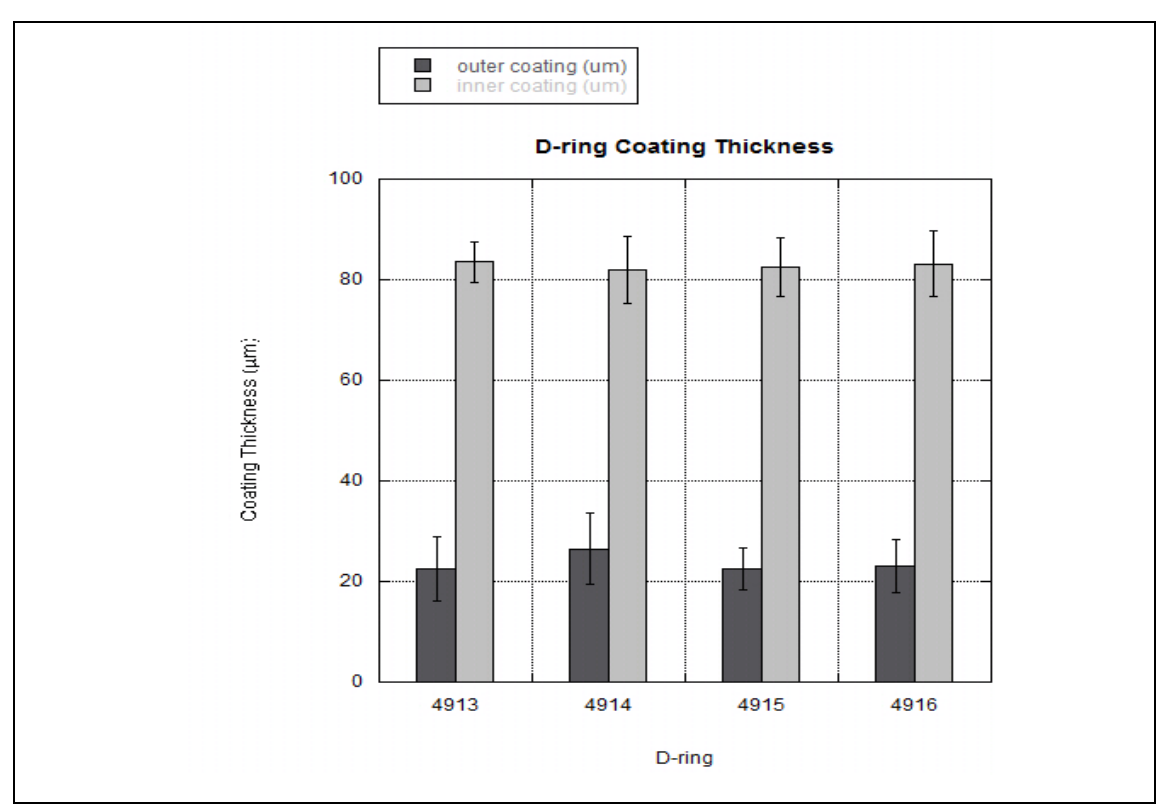

FIGURE 40 Aluminum (outer) and Nickel (inner) Coating Thicknesses for the Four D-ring Samples. 


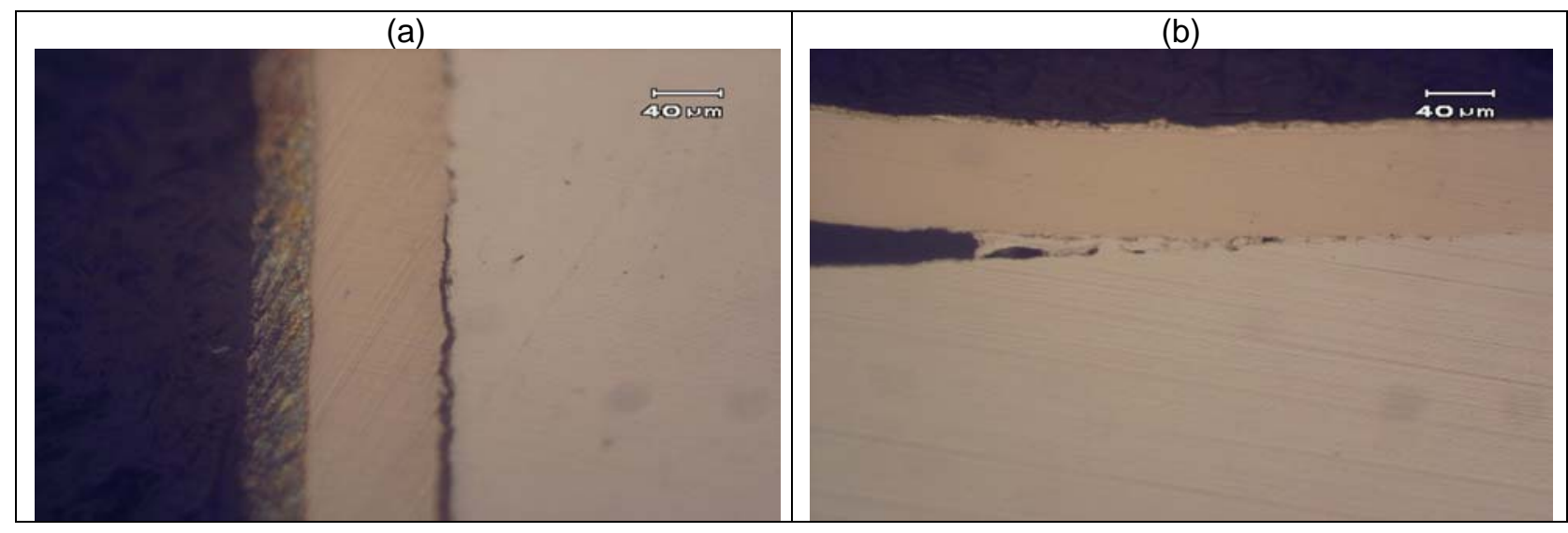

FIGURE 41 Damage Observed in the Coatings: (a) Delamination at the Nickel/Steel Interface and (b) Delamination at Nickel/Steel Interface and No Aluminum.

\subsection{SUMMARY}

- $\quad$ The hardness of the aluminum-coated yokes was $\mathrm{R}_{\mathrm{c}} \sim 25-35$.

- The hardness of the aluminum-coated D-ring was $\mathrm{R}_{\mathrm{c}} \sim 32$.

- Measured coating thicknesses for aluminum and nickel in the yoke samples were $22 \mu \mathrm{m}$ (0.9 mils) and $80 \mu \mathrm{m}$ (3 mils), respectively. D-rings also showed similar coating thicknesses.

- The variation in aluminum coating thickness was quite large, particularly for the yoke samples.

- A few areas on the polished cross sections showed damage to the aluminum and nickel coatings. These observations are likely an artifact of sample preparation. 


\section{SUMMARY}

A detailed study was conducted to understand the mechanism(s) that may have contributed to the in-service failure of the yoke used as part of the beam clamp assembly for the HLLs at the K-25 plant in Oak Ridge, TN. Based on this investigation several recommendations were made. Subsequently, the improved beam clamp assemblies were evaluated to ensure they meet the recommendations.

The main conclusions from this study are as follows:

- Corrosion products from the failed yokes showed measurable amounts of calcium, sulfur, and zinc by both EDAX and chemical analysis. Failure was primarily intergranular. Corrosion products were also observed on the fracture surface of the failed yoke.

- Galvanic corrosion is the possible yoke failure mechanism. It appears that a galvanic couple formed between the zinc-coated components (D-ring, anode) and the bare steel surface of the yoke (cathode) during service conditions. The presence of ions (sulfate) in the rainwater created an electrolytic medium for the galvanic cell. Further, on the yoke side, the iron reacted to form iron hydroxide, which can oxidize in air to form iron oxide that gives the red rust color seen on the failed yoke.

- In the presence of mechanical stress, the corrosion process can be accelerated, leading to a catastrophic failure.

- Galvanic corrosion can be inhibited by coating the yoke with a metal that is more anodic than zinc, such as aluminum.

- Upon reviewing several reports and email correspondences provided by BJC, the failure of the yokes was also suggested to be a result of hydrogen embrittlement. Since hydrogen (as a result of corrosion) can diffuse into the martensitic stainless steel, it could render the material brittle, leading to catastrophic failure.

- Hydrogen analysis conducted on the failed yoke samples indicated the hydrogen content to be of the same level as that of the as-received steel. However, as suggested by Mr. T. Knaub of Bechtel, because of the elapsed time between failure of the yoke and analysis of the samples (3-4 months), elemental hydrogen would have diffused out of the corroded yoke sample.

- Bechtel Jacobs instituted a plan to dual coat the beam clamp components with a nickel (10 wt.\% phosphorus) coating followed by an aluminum coating. The yoke and D-ring components were coated with nickel (with 10\% phosphorus) 
to inhibit or delay the corrosion process and limit ingress of hydrogen into the steel. An aluminum coating was used to prevent galvanic corrosion.

- Evaluation of the dual nickel-and-aluminum coated yoke and D-rings specimens met the recommendations.

- The hardness values of dual coated yokes were $\mathrm{R}_{\mathrm{C}} \sim 25-35$. Hardness values of dual-coated D-ring were $\mathrm{R}_{\mathrm{C}} \sim 32$.

- Measured average coating thicknesses for the aluminum and nickel coatings on the yoke samples were $22 \mu \mathrm{m}$ (0.9 mils) and $80 \mu \mathrm{m}$ (3 mils), respectively. D-rings also showed similar coating thicknesses.

- Microscopic examination showed that the aluminum coating was well bonded to the underlying nickel coating. Some observed damage was believed to be an artifact of the cutting-and-polishing actions during sample preparation for microscopy.

- To ensure that no further corrosion and subsequent failure of the modified beam clamp components will occur over the service life-times, a long-term corrosion testing is recommended. Long-term and/or accelerated corrosion tests should be conducted on the dual coated beam-clamp components under identical environmental conditions (temperature, water, stress, etc.) as the inservice conditions. Such tests will provide information the in-service accurate life-times of the beam clamp components. 


\section{REFERENCES}

1. T. Knaub, email report to A. Dada, "Beam Clamp Failure - Horizontal Life Lines (HLL)," Sept. 15, 2009.

2. A. Dada, results on rainwater sample analysis provided by email to ANL, Oct. 23, 2009.

3. M.G. Fontana and N.D. Greene, in Corrosion Engineering, Chapter 9, pp. 297-324, McGraw-Hill, New York (1978).

4. T. Knaub, meeting at Bechtel Jacob’s Office, Fredrick, Md., Dec. 8, 2009. 
Argonne

Nuclear Engineering Division

Argonne National Laboratory

9700 South Cass Avenue, Bldg. 208

Argonne, IL 60439-4842

www.anl.gov 